\title{
Kinetics of the Chromium(III)/L-Glutamic Acid Complexation Reaction: Formation, Decay, and UV-Vis Spectrum of a Long-Lived Intermediate
}

JOAQUIN F. PEREZ-BENITO, JOAN NICOLAS-RIVASES

Departamento de Ciencia de Materiales y Quimica Fisica, Seccion de Quimica Fisica, Facultad de Quimica, Universidad de Barcelona, Marti i Franques, 1, 08028 Barcelona, Spain

Correspondence to: J. F. Perez-Benito; e-mail: jfperezdebenito@ub.edu.

Supporting Information is available in the online issue at www.wileyonlinelibrary.com. 
ABSTRACT: The kinetics of the aqueous reaction of $\mathrm{Cr}$ (III) with either L-glutamic acid or sodium hydrogen L-glutamate at $\mathrm{pH} 2.46-5.87$ have been followed by means of absorbance readings. The rate of formation of the reaction products showed acceleration- deceleration periods, caused by the accumulation and posterior decay of an intermediate in non-negligible concentration. A double-exponential integrated rate law allowed obtaining two rate constants for each absorbance-time experimental series, associated with the appearance $\left(k_{1}\right)$ and decay $\left(k_{2}\right)$ of the long-lived intermediate. An increase of the initial concentrations of either hydrogen L-glutamate (apparent kinetic orders $<1$ ) or hydroxide (kinetic orders $=1$ ) ions resulted in an increase of both $k_{1}$ and $k_{2}$, but addition of an inert electrolyte $\left(\mathrm{KNO}_{3}\right)$ resulted in opposite effects on $k_{1}$ (decrease) and $k_{2}$ (increase). The experimental activation energies were $83 \pm 10$ (for $k_{1}$ ) and $95 \pm 5$ (for $k_{2}$ ) $\mathrm{kJ} \mathrm{mol}^{-1}$. The electronic spectrum of the low reactivity, detected intermediate resembled more closely that of the blue/green reactant than that of the violet reaction product. The low number of protons set free by the complexating hydrogen Lglutamate ligand seems to suggest that some polymerization of the coordinated amino acid (to form a di- or tripeptide) might take place. The available experimental data indicate that the coordination of the organic ligand must be preceded by the breakdown of a strong $\mathrm{Cr}(\mathrm{III})$ $\mathrm{H}_{2} \mathrm{O}$ chemical bond in the slow steps of the mechanism. 


\section{INTRODUCTION}

Chromium(III) is interesting to chemists, partially because of the diversity and stability of its complexes [1], but also because it constitutes the final oxidation state from most $\mathrm{Cr}(\mathrm{VI})$ oxidations [2-4]. Moreover, it is interesting to biologists, given that $\mathrm{Cr}(\mathrm{III})$ is arguably a mineral trace nutrient necessary for the correct metabolization of sugars [5,6] through its involvement in the structure of the glucose tolerance factor [7-9]. Although the chemical nature of this biomolecule is yet to be elucidated, nicotinic acid and glutathione (an Lglutamic acid containing peptide) are believed to act as the organic ligands of $\mathrm{Cr}(\mathrm{III})$. Hence, supplementation by this oligo element might be beneficial in the treatment of a widespread disease such as type 2 diabetes [10,11]. The Cr(III)-amino acid biocomplex chromodulin was initially thought to participate also in the carbohydrate metabolism through regulation of the insulin receptor signal [12], but there is currently some debate on the actual importance of this metal as a trace nutrient $[13,14]$. Albeit supplementation by $\mathrm{Cr}(\mathrm{III})$ might have a role in antiaging medicine, for it has been reported to lead to a notable enhancement of the lifespan (both median and maximum) of rodents [15], overdoses of this transition metal should be avoided due to some potential adverse side effects [16].

L-glutamic acid, for its part, is considered as one of the 11 nonessential amino acids because of the human body ability to synthesize it [17]. Besides its important property of behaving as an excitatory neurotransmitter for the central nervous system, its involvement in the formation of the tripeptide glutathione renders this amino acid crucial as a building block of the living cell antioxidant defenses [18,19], especially as far as the hydrogen peroxide and lipid hydroperoxide scavenging enzymes of the glutathione peroxidase type are concerned [20]. Moreover, in the form of monosodium glutamate (or sodium hydrogen L-glutamate), it 
has been authorized as a food additive (E-621) due to its special quality of acting as a flavor enhancer [21].

The octahedral $\mathrm{Cr}$ (III) complexes are inert to substitution [22-24]. Therefore, the kinetics of their slow reactions of ligand replacement can be studied by conventional techniques. In particular, kinetic studies on the complexation of $\mathrm{Cr}$ (III) by some $\alpha$-amino acids have been reported $[25,26]$. These reactions might be tangentially related to the problem of the origin of the first peptides on prebiotic Earth [27], since transition metal ions have been shown to catalyze the formation of peptide bonds between the amino acid monomers acting as ligands [28].

In the work now presented, some deviations from the one rate constant kinetic model reported for the $\mathrm{Cr}(\mathrm{III})$-amino acid complexation reactions have been observed. This kind of kinetic deviations might also affect the reactions of $\mathrm{Cr}$ (III) with picolinic acid [29], EDTA [30-32], and other similar organic ligands [33]. As will be shown hereafter for the particular case of the complexation of $\mathrm{Cr}$ (III) with L-glutamic acid, a mathematical model involving two rate constants might be a better alternative to study the kinetics of these reactions.

\section{EXPERIMENTAL}

Milli-Q quality water was the solvent chosen in all the experiments. The reactants were purchased either from Merck $\left[\mathrm{Cr}\left(\mathrm{NO}_{3}\right)_{3} \cdot 9 \mathrm{H}_{2} \mathrm{O}, \mathrm{KOH}\right.$, and $\left.\mathrm{KNO}_{3}\right]$ or Sigma-Aldrich [HOOC$\mathrm{CH}\left(\mathrm{NH}_{2}\right)-\left(\mathrm{CH}_{2}\right)_{2}-\mathrm{COOH}$ and $\left.\mathrm{HOOC}-\mathrm{CH}\left(\mathrm{NH}_{2}\right)-\left(\mathrm{CH}_{2}\right)_{2}-\mathrm{COONa}\right]$, and were used without further purification. The complexing agent was in large excess with respect to $\mathrm{Cr}$ (III) in most kinetic experiments. The $\mathrm{pH}$ was measured at the end of the kinetic runs with the aid of a Metrohm 605 pH-meter. The absorbance readings were made with a Shimadzu 160 A UV-Vis 
spectrophotometer and the UV-Vis spectra were recorded with an SI Analytics $8100 \mathrm{UV}-\mathrm{Vis}$ spectrophotometer. The wavelength chosen to follow the advancement of the reactions was that corresponding to the highest increase of the absorbance from $t=0$ to $t=\infty$, it depended on the initial experimental conditions and fell within the range $530 \mathrm{~nm}-555 \mathrm{~nm}$. Reproducibility was tested by duplication of all the experimental measurements (total number of kinetic experiments performed: 137).

\section{RESULTS AND DISCUSSION}

\section{Long-Lived Intermediate: Experimental Evidences}

First Proof. Periodic scannings of the UV-Vis spectrum of the reacting mixture, with either Lglutamic acid (Fig. 1, top) or sodium hydrogen L-glutamate (Fig. 1, bottom) as source of organic ligands, were recorded. The higher solubility of the second reactant allowed performing the experiment with a higher concentration of the ligand. However, the different time frames of the two experiments were mainly caused by the higher $\mathrm{pH}$ in the second case. Although no perfect isosbestic point (IP) was observed, one approximate IP was observed in the first case and three in the second, the wavelength corresponding to one of the three faux IPs decreasing gradually from 483.5 to $457.5 \mathrm{~nm}$ as the reaction advanced. Since the occurrence of perfect IPs requires (besides a reactant and a product with the same molar absorption coefficients at a particular wavelength) that all the intermediates involved in the mechanism be very reactive (in steady state), the shift of that IP toward lower wavelengths means that at least one of the reaction intermediates is long lived enough to be in a nonnegligible concentration. 
Second Proof. When the source of organic ligands was L-glutamic acid ( $\mathrm{pH} 2.59)$, the absorbance at $470 \mathrm{~nm}$ was almost constant over time (approximate isosbestic point). However, when the source was sodium hydrogen L-glutamate ( $\mathrm{pH} 4.68)$, the absorbance at that wavelength first decreased, passed through a minimum, and then increased (Fig. 2). Since, if all the intermediates were in steady state the absorbance would either decrease or increase monotonously throughout the reaction (depending on the molar absorption coefficient of the product being lower or higher than that of the reactant at that particular wavelength, respectively), this can be taken as another proof of the involvement of a longlived intermediate in the mechanism.

Third Proof. Although a plot of the absorbance at $410 \mathrm{~nm}$ versus the absorbance at $545 \mathrm{~nm}$ as the reaction advanced was linear, a plot of the absorbance at $580 \mathrm{~nm}$ versus that at $545 \mathrm{~nm}$ showed a downward-concave curvature (incompatible with all the intermediates involved being reactive enough to be in steady state, Fig. 3). Effectively, it is easy to demonstrate that, if all the intermediates were very reactive (in steady state), the absorbances at two different wavelengths should be linearly related (this is a consequence of the Lambert-Beer law and a simple mass balance). Those wavelengths were chosen so that they were coincident with two absorption maxima of either the reactant $(410$ and $580 \mathrm{~nm})$ or the product (410 and $545 \mathrm{~nm})$.

Fourth Proof. The absorbance-time curves showed a sigmoidal profile (Fig. 4) and the rate-time curves a bell-shaped one (Fig. 5). Although these features are also compatible with autocatalysis, this kind of process is to be expected for reactions involving considerably reactive products [34-36] or intermediates [37] rather than for the ligand replacement reactions from the notably inert $\mathrm{Cr}(\mathrm{III})$ complexes. Thus, the long-lived intermediate based explanation should be considerd more probable in the present case. Moreover, the computer simulations made to fit the experimental kinetic data indicated that they adjusted to a double- 
exponential function typical of pseudo-first order consecutive reactions involving a long-lived intermediate [38].

\section{Double-Exponential Kinetic Fits}

The available experimental data on the reaction supported the use of the following simplified mechanism:

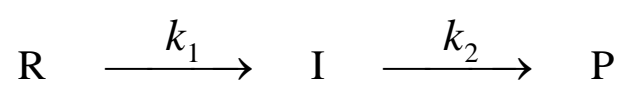

the concentrations of reactant, intermediate, and product during the course of the reaction being given by the equations:

$$
\begin{gathered}
{[\mathrm{R}]=[\mathrm{R}]_{\mathrm{o}} e^{-k_{1} t}} \\
{[\mathrm{I}]=\frac{k_{1}[\mathrm{R}]_{\mathrm{o}}}{k_{2}-k_{1}}\left(e^{-k_{1} t}-e^{-k_{2} t}\right)} \\
{[\mathrm{P}]=[\mathrm{R}]_{\mathrm{o}}-[\mathrm{R}]_{\mathrm{o}} e^{-k_{1} t}-\frac{k_{1}[\mathrm{R}]_{\mathrm{o}}}{k_{2}-k_{1}}\left(e^{-k_{1} t}-e^{-k_{2} t}\right)}
\end{gathered}
$$

and the absorbance reading at a particular wavelength:

$$
A_{\lambda}=\left(\varepsilon_{\mathrm{R}, \lambda}[\mathrm{R}]+\varepsilon_{\mathrm{I}, \lambda}[\mathrm{I}]+\varepsilon_{\mathrm{P}, \lambda}[\mathrm{P}]\right) l
$$


where $l=1 \mathrm{~cm}$ stands for the length of the light path. The molar absorption coefficients of reactant, intermediate, and product could be obtained as:

$$
\begin{aligned}
\varepsilon_{\mathrm{R}, \lambda} & =\frac{A_{\lambda, 0}}{[\mathrm{R}]_{\mathrm{o}} l} \\
\varepsilon_{\mathrm{I}, \lambda} & =\mathrm{Q} \varepsilon_{\mathrm{R}, \lambda} \\
\varepsilon_{\mathrm{P}, \lambda} & =\frac{A_{\lambda, \infty}}{[\mathrm{R}]_{\mathrm{o}} l}
\end{aligned}
$$

where $A_{\lambda, 0}$ and $A_{\lambda, \infty}$ are the absorbances at $t=0$ and $t=\infty$, respectively, and the ratio between the molar absorption coefficients of the long-lived intermediate and reactant could be optimized from the fits of the absorbance-time kinetic data corresponding to two independent experiments as $Q=1.089 \pm 0.009$. Then, the $A_{\lambda}$ vs $t$ data for all the kinetic runs were fitted to Eqs. (2) -(8) using different combinations of 4 fitting parameters $\left(A_{\lambda, 0}, A_{\lambda, \infty}, k_{1}\right.$, and $\left.k_{2}\right)$ whose values were systematically varied until minimization of the average error associated to the fit was achieved, the latter being defined as:

$$
E=\frac{\sum_{\mathrm{i}=1}^{N}\left|A_{\mathrm{i}, \mathrm{cal}}-A_{\mathrm{i}, \exp }\right|}{N}
$$


where $A_{\mathrm{i}, \mathrm{cal}}$ and $A_{\mathrm{i} \text { exp }}$ are the calculated and experimental absorbances, respectively, and $N$ the number of absorbance-time couples measured for the corresponding experiment. The errors were in the range $E=2.94 \times 10^{-4}-1.65 \times 10^{-3}$. The quality of the fit for a typical experiment is compared in Fig. 6 with that attained by the pseudo-first order kinetic model proposed by other authors [26]. The concordance between the experimental absorbances and those calculated according to the double-exponential function at different initial concentrations of metal ion is shown in Fig. 7.

\section{Kinetic Results}

Both $k_{1}$ and $k_{2}$ decreased as the initial concentration of metal ion increased under a large, constant excess of sodium hydrogen L-glutamate (Table I). Since, in the absence of experimental errors, the rate constants should be independent of the initial concentration of the limiting reactant, this behavior must be interpreted as a systematic error. This variation of the rate constants can be ascribed to the decrease of the $\mathrm{pH}$ as the reaction advanced caused by the release of protons from the amino acid to coordinate with $\mathrm{Cr}$ (III), suggesting the involvement of base catalysis that was confirmed later by independent experiments. Actually, the occurrence of systematic experimental errors leading to rate coefficients showing a dependence on the value of the limiting reactant initial concentration is somehow ubiquitous in kinetic studies, especially when two [39-41] or three [42] rate constants are required to account for the observed absorbance vs time curves. Therefore, the rate constants obtained in this work must be considered as average values for the $\mathrm{pH}$ range covered in each kinetic experiment. 
Both $k_{1}$ and $k_{2}$ decreased as the initial concentration of L-glutamic acid increased, due to the $\mathrm{pH}$ decrease associated (a second sign of base catalysis). This allowed concluding that the reaction rate was more sensitive to the solution $\mathrm{pH}$ than to the ligand initial concentration. When the source of organic ligands was sodium hydrogen L-glutamate instead, both rate constants increased when its initial concentration increased, following double-reciprocal linear relationships (Fig. 8). This kind of law has often been reported not only in complexation reactions [39], but also when acid-base equilibria [43] or heterogeneous processes $[44,45]$ are involved.

In order to study the effect of the medium ionic strength on the reaction rate, $\mathrm{KNO}_{3}$ was chosen as background electrolyte, due to the well-known poor ability of nitrate ion to act as a potential ligand in competition with L-glutamate ion. Although the dispersion of the kinetic data did not allow to precise the kind of relationship existing between the rate constants and the ionic strength, the data did allow concluding that, whereas rate constant $k_{1}$ decreased with increasing ionic strength, $k_{2}$ increased. This opposite behavior of the two rate constants matched that observed for the Cr(III)-EDTA complexation reaction [39].

The logarithms of both rate constants increased linearly with the $\mathrm{pH}$ (Fig. 9), the corresponding slopes being $0.98 \pm 0.08$ (for $k_{1}$ ) and $1.03 \pm 0.07$ (for $k_{2}$ ), leading to the conclusion that both the formation of the long-lived intermediate and its decay were of first order in hydroxide ion.

Both rate constants fulfilled the Arrhenius equation (Fig. 10), and the activation parameters (Table II) indicated that the slow step (higher activation energy) was the decay of the longlived intermediate into the reaction products. This is consistent with the finding that rate constant $k_{2}$ was one order of magnitude lower than $k_{1}$ in most experiments. 


\section{UV-Vis Spectrum of the Long-Lived Intermediate}

The periodic scannings shown in Fig. 1 were used to obtain the electronic spectrum of the long-lived intermediate. To that end, the maximum concentration of the intermediate and the instant at which it was reached were calculated from Eq. (3) as:

$$
\begin{aligned}
{[\mathrm{I}]_{\max } } & =\frac{k_{1}}{k_{2}}[\mathrm{R}]_{\mathrm{o}} e^{-k_{1} t_{\max }} \\
t_{\max } & =\frac{1}{k_{1}-k_{2}} \ln \frac{k_{1}}{k_{2}}
\end{aligned}
$$

Application of Eqs. (10) and (11) to the kinetic experiments corresponding to Fig. 1 allowed the estimation of both $t_{\max }$ and $[\mathrm{I}]_{\max }$ for each of these particular cases. Interpolation between the two intermediary spectra closer to that instant led to the spectrum of the reacting mixture at the exact moment when the long-lived intermediate exhibited its maximum concentration. Then, the molar absorption coefficient of the intermediate at each wavelength could be obtained by discounting from the total absorbance $\left(A_{\lambda}\right)$ the contributions of the other two chemical species absorbing light:

$$
\varepsilon_{\mathrm{I}, \lambda}=\frac{A_{\lambda}-\left(\varepsilon_{\mathrm{R}, \lambda}[\mathrm{R}]_{\max }+\varepsilon_{\mathrm{P}, \lambda}[\mathrm{P}]_{\max }\right) l}{[\mathrm{I}]_{\max } l}
$$

$[R]_{\max }$, obtained from Eq. (2), and $[P]_{\max }$, obtained from Eq. (4), being the concentrations of reactant and product, respectively, at the instant $t_{\max }$, whereas the other symbols have the 
same meaning than in Eq. (5). The results obtained from Eq. (12) have been plotted in order to be compared with the spectral data experimentally accessible for the inorganic reactant and the final product (Fig. 11).

It can be concluded that the spectrum of the long-lived intermediate is much more similar to that of the inorganic reactant than to that of the product, thus meaning that the chemical structure of the intermediate must be rather close to that of the reactant $\mathrm{Cr}(\mathrm{III})$. This seems to suggest that the intermediate involves only one L-glutamate ligand (probably, bidentate), with an oxygen atom from the C5 carboxylate group and a nitrogen atom from the amino group acting as electron-pair donors to the metal ion placed in the center of the octahedron, and still retaining 4 water molecules as ligands. Moreover, the similarity between the spectra of $\left[\mathrm{Cr}\left(\mathrm{H}_{2} \mathrm{O}\right)_{6}\right]^{3+} /\left[\mathrm{Cr}(\mathrm{OH})\left(\mathrm{H}_{2} \mathrm{O}\right)_{5}\right]^{2+}$ and the long-lived intermediate suggests that the use of a value for parameter $Q$ very close to unity $(1.089 \pm 0.009$, as obtained for two independent kinetic runs) for all the experiments is a good enough approximation.

\section{Number of Organic Ligands}

The UV-Vis spectra recorded for the final violet reacting mixture indicated that the wavelength corresponding to the first absorption peak lied in the range $394-410 \mathrm{~nm}$ and that corresponding to the second peak in the range $534-568 \mathrm{~nm}$, increasing both with the initial concentration of metal ion (Fig. 12, bottom) and decreasing both with the initial concentration of organic ligand (Fig. 13, bottom), whereas the maximum absorbances increased in both cases (Figs. 12 and 13, top), 
Although the existence of only one complex of $\mathrm{Cr}$ (III) with L-glutamic acid has been reported (with the stoichiometric ratio $1: 3$ for metal ion : organic ligand) [26], the above results cannot be explained unless we assume the presence of at least two different complexes in the final reacting mixture. Thus, although the participation of other complexes cannot be discarded, the simplest explanation for the experimental data so far available is that two complexes differing in the number of organic ligands coexist in equilibrium in the final reacting mixture:

$$
\mathrm{C}_{n}+\mathrm{Glu} \stackrel{K}{\rightleftarrows} \mathrm{C}_{n+1}
$$

where $\mathrm{C}_{n}$ and $\mathrm{C}_{n+1}$ are $\mathrm{Cr}(\mathrm{III})$ complexes involving $n$ and $n+1$ L-glutamate ligands, respectively, their concentrations being present in the ratio:

$$
\frac{\left[\mathrm{C}_{n+1}\right]}{\left[\mathrm{C}_{n}\right]}=K[\mathrm{Glu}]=K\left\{[\mathrm{Glu}]_{\mathrm{T}}-n\left[\mathrm{C}_{n}\right]-(n+1)\left[\mathrm{C}_{n+1}\right]\right\}
$$

where $[\mathrm{Glu}]$ and $[\mathrm{Glu}]_{\mathrm{T}}$ stand for the concentrations of free and total amino acid, respectively.

Since an increase of the metal ion initial concentration results in an increase of the concentrations of both complexes $\mathrm{C}_{n}$ and $\mathrm{C}_{n+1}$, and so in a decrease of the concentration of the free amino acid (a decrease of the $\left[\mathrm{C}_{n+1}\right] /\left[\mathrm{C}_{n}\right]$ ratio), whereas an increase of the organic ligand initial concentration $\left([\mathrm{Glu}]_{\mathrm{T}}\right.$ ) leads to the opposite result (an increase of both the free amino acid concentration and the $\left[\mathrm{C}_{n+1}\right] /\left[\mathrm{C}_{n}\right]$ ratio), Eq. (14) is consistent with the plots shown in Figs. 12 and 13 provided that the electronic spectra corresponding to the different 
complexes are shifted toward lower wavelengths as the number of organic ligands increases and, at the same time, there is an enhancement of the intensity of the absorption peaks:

$$
\begin{aligned}
& \lambda_{1,2}(0)>\lambda_{1,2}(n)>\lambda_{1,2}(n+1) \\
& \varepsilon_{1,2}(0)<\varepsilon_{1,2}(n)<\varepsilon_{1,2}(n+1)
\end{aligned}
$$

In the inequalities written in Eqs. (15) and (16) the subscripts indicate that the wavelengths and molar absorption coefficients correspond to both peaks of the spectrum (the first and the second) and the quantities within parentheses stand for the number of organic ligands involved in each of the four complexes proposed: 0 for the initial inorganic reactant, either blue $\left[\mathrm{Cr}\left(\mathrm{H}_{2} \mathrm{O}\right)_{6}\right]^{3+}$ or green $\left[\mathrm{Cr}(\mathrm{OH})\left(\mathrm{H}_{2} \mathrm{O}\right)_{5}\right]^{2+}, n$ for the final violet complex $\mathrm{C}_{n}$, and $n+1$ for the final violet complex $\mathrm{C}_{n+1}$. This hypothesis, besides being in agreement with the experimental data, seems quite logical, since, as the number of organic ligands coordinated to $\mathrm{Cr}$ (III) increases (from 0 to $n$, and from $n$ to $n+1$ ) and the number of water ligands decreases, the UV-Vis spectrum distances itself progressively from that corresponding to the inorganic reactant (the wavelengths decrease and the maximum absorbances increase).

\section{Number of Hydrogen Ions Released}

The $\mathrm{pH}$ experimental values measured at the end of the kinetic runs for different ligand/metal initial concentration ratios were used to calculate the number of hydrogen ions released to the medium by sodium hydrogen L-glutamate per chromium atom to form the final violet complex. The formula required to perform those calculations was: 


$$
\operatorname{Number}\left(\mathrm{H}^{+}\right)=\left(\frac{[\text { ligand }]_{\mathrm{o}}-n[\mathrm{Cr}(\mathrm{III})]_{\mathrm{o}}}{K_{\mathrm{a}}+\left[\mathrm{H}^{+}\right]_{\infty}}+1\right) \frac{\left[\mathrm{H}^{+}\right]_{\infty}}{[\mathrm{Cr}(\mathrm{IIII})]_{\mathrm{o}}}
$$

where the numerator in the first fraction is the concentration of free hydrogen L-glutamate ion for an assumed ligand/metal coordination number $n$, whereas $K_{\mathrm{a}}$ is the second aciddissociation equilibrium constant of L-glutamic acid $\left(\mathrm{p} K_{\mathrm{a}}=4.07\right.$ at $\left.25.0{ }^{\circ} \mathrm{C}\right)$ [46].

At low ligand/metal ratios, there was not enough excess of organic substrate to act as a good buffer (scavenging the released $\mathrm{H}^{+}$), so that some information on the amino acid actually coordinated to $\mathrm{Cr}$ (III) could be obtained. Assuming different coordination numbers $(n=$ 0-3), curves with distinct patterns were produced (Fig. 14). Since the UV-Vis spectra recorded at the end of the kinetic runs revealed the existence of two or more complexes in equilibrium, the possibility arises that the complexes might correspond to coordination numbers $n=0$ and $n=1$ and, so, that the global reaction might be reversible, with some free $\mathrm{Cr}(\mathrm{III})$ in equilibrium with a mono-coordinated L-glutamate complex. However, the curves corresponding to those coordination numbers would imply a decrease in the number of hydrogen ions released at low $[\text { ligand }]_{\mathrm{o}} /[\mathrm{Cr}(\mathrm{III})]_{\mathrm{o}}$ ratios that would be very hard to explain. Effectively, it can be reasonably expected that an increase in the ligand/metal ratio should result in an increase of the average coordination number $n$ and, so, in an increase of the number of hydrogen ions released to the medium per chromium atom. Actually, this is the pattern found in the case of the $\mathrm{Cr}(\mathrm{III})$-EDTA complexation reaction [39]. Thus, the behavior reflected in the plots shown in Fig. 14 strongly suggests that that the lowest coordination number in the final reacting mixture is $n \geq 2$ and that the global reaction is essentially irreversible. The latter conclusion is consistent with the high value reported for the formation equilibrium constant of the analogous $\mathrm{Cr}(\mathrm{III})$-EDTA complex $\left(\log K_{\mathrm{f}}=23\right)[31,47]$. Thus, the 
most probable values for the number of organic ligands in the final violet complexes shown in Eq. (13) are $n=2$ and $n+1=3$.

Additional information of potential interest is the rather low asymptotic value of the number of hydrogen ions released at high ligand/metal initial concentration ratios:

$$
\lim _{[\text {ligand }]_{0} /[\text { metal }]_{0} \rightarrow \infty} \operatorname{Number}\left(\mathrm{H}^{+}\right)=1.29
$$

According to the above argument, the lowest coordination numbers seem to be $n=2$ (predominant at low ligand/metal initial concentration ratios) and $n=3$ (predominant at high ligand/metal initial concentration ratios). This is partially consistent with the value $n=3$ previously reported [26]. Hence, provided that the nitrogen atom of the amino acid be coordinated to $\mathrm{Cr}$ (III) (and the resemblance of the present complexes with those of $\mathrm{Cr}^{3+}$ with EDTA [48-50] and EDTA-type [51] ligands seems to indicate so), the number of hydrogen ions released to the medium per chromium atom (due to the required deprotonation of the corresponding ammonium groups) would be expected to be at least 2 (at low ligand/metal ratios) or 3 (at high ligand/metal ratios) when the source of organic ligands was sodium hydrogen L-glutamate. A possible explanation would be the potential formation of a Glu-Glu dipeptide or a Glu-Glu-Glu tripeptide following the coordination of 2 or 3 organic ligands to the metal ion. This would leave just one ammonium group per peptide chain. In the case that the peptide bond formation between the coordinated amino acid ligands was complete, the number of hydrogen ions released would be exactly 1 (the remaining hydrogen atoms being released as water molecules during the condensation process). Thus, the experimental value of 1.29 (Eq. (18)), might indicate that the amino acid polymerization was only partial. Actually, 
transition metal ions (such as $\mathrm{Cu}^{2+}$ and $\mathrm{Zn}^{2+}$ ) are known to catalyze the formation of small peptides from free amino acids $[52,53]$ or their ester derivatives [54].

\section{Mechanism}

The kinetic data obtained in the laboratory for the complexation reaction indicated that the first experimental rate constant $\left(k_{1}\right)$ was one order of magnitude higher than the second $\left(k_{2}\right)$, and the corresponding activation energies were coherent with these results $\left(E_{\mathrm{a}, 1}<E_{\mathrm{a}, 2}\right)$. Thus, the step (not necessarily elementary) leading to the formation of the intermediate is fast whereas that leading to its decay is slow, what certainly explains the long-lived nature of that intermediate. Actually, that intermediate divides the reaction mechanism in two elementary reaction sequences, being possible the application of approximate methods (quasi-equilibrium and steady state [55]) within each of them.

The mechanism that can be proposed for the first part of the complexation (from the reactants to the long-lived intermediate) consists of the following elementary steps:

$$
\begin{aligned}
& {\left[\mathrm{Cr}\left(\mathrm{H}_{2} \mathrm{O}\right)_{6}\right]^{3+} \stackrel{K_{\mathrm{I}}}{\rightleftarrows}\left[\mathrm{Cr}(\mathrm{OH})\left(\mathrm{H}_{2} \mathrm{O}\right)_{5}\right]^{2+}+\mathrm{H}^{+}} \\
& {\left[\mathrm{Cr}(\mathrm{OH})\left(\mathrm{H}_{2} \mathrm{O}\right)_{5}\right]^{2+} \stackrel{k_{\text {II }} \text { (slow) }}{\rightleftarrows}\left[\mathrm{kr}(\mathrm{OH})\left(\mathrm{H}_{2} \mathrm{O}\right)_{4}\right]^{2+}+\mathrm{H}_{2} \mathrm{O}} \\
& {\left[\mathrm{Cr}(\mathrm{OH})\left(\mathrm{H}_{2} \mathrm{O}\right)_{4}\right]^{2+}+\mathrm{H}_{2} \mathrm{YO}^{-} \stackrel{k_{\mathrm{III}}}{\longrightarrow} \quad\left[\mathrm{Cr}(\mathrm{OH})\left(\mathrm{H}_{2} \mathrm{YO}\right)\left(\mathrm{H}_{2} \mathrm{O}\right)_{4}\right]^{+}} \\
& {\left[\mathrm{Cr}(\mathrm{OH})\left(\mathrm{H}_{2} \mathrm{YO}\right)\left(\mathrm{H}_{2} \mathrm{O}\right)_{4}\right]^{+} \longrightarrow\left[\mathrm{Cr}(\mathrm{HYO})\left(\mathrm{H}_{2} \mathrm{O}\right)_{4}\right]^{+}+\mathrm{H}_{2} \mathrm{O}}
\end{aligned}
$$


where $\mathrm{H}_{2} \mathrm{YO}^{-}$stands for hydrogen L-glutamate ion $(\mathrm{H}$ being hydrogen atoms belonging to the ammonium group and $\mathrm{O}$ an oxygen atom belonging to one of the carboxylate groups). The experimental results show that the reaction rate presents a much stronger dependence on the concentration of hydroxide ion than on that of the organic ligand. This seems to suggest that the deprotonation associated with the observed base catalysis happens in a previous step, independent of the coordination of the ligand to the metal ion. Consequently, the proposed reaction sequence starts with the well-known acid-base equilibrium of hexaaquachromium(III) ion to yield hydroxopentaaquachromium(III) ion (Eq. (19), p $K_{\mathrm{a}} 4.29$ ) [56,57]. The presence of an $\mathrm{OH}^{-}$ligand in the hydroxo complex renders the $\mathrm{Cr}(\mathrm{III})-\mathrm{H}_{2} \mathrm{O}$ chemical bonds more labile. The breakage of one of those bonds as in Eq. (20) has been postulated to be a requirement for the formation of the Cr(III)-EDTA complex [32]. Then, a competition between water (reverse direction of Eq. (20)) and the organic ligand (Eq. (21)) for the vacant coordination site of the metal ion takes place. Afterwards, the loss of a second water molecule allows the transition of the organic ligand from monodentate to bidentate, leading to the formation of the long-lived intermediate (Eq. (22)).

Assuming that the penta-coordinated intermediate is reactive enough to be in steady state (in other words, that it is formed in the slow step, forward direction of Eq. (20)), and applying to Eq. (19) the quasi-equilibrium approximation, the following expression can be obtained for the first experimental rate constant:

$$
k_{1}=\frac{K_{\mathrm{I}} k_{\mathrm{II}} k_{\mathrm{III}}\left[\mathrm{H}_{2} \mathrm{YO}^{-}\right]}{\left(k_{-\mathrm{II}}+k_{\mathrm{III}}\left[\mathrm{H}_{2} \mathrm{YO}^{-}\right]\right)\left[\mathrm{H}^{+}\right]}
$$


Equation (23) is consistent with the results corresponding to the dependences of $k_{1}$ on the concentrations of organic ligand (double-reciprocal linear plot with positive intercept, Fig. 8, top) and hydrogen ion (Fig. 9, top). Moreover, the decreasing effect of the ionic strength can be explained by the associated decrease of both equilibrium constant $K_{\mathrm{I}}$ (since the reverse direction of Eq. (19) involves two like-charged ions as reactants) and rate constant $k_{\mathrm{III}}$ (since Eq. (21) involves two unlike-charged ions as reactants).

On the other hand, the mechanism that can be proposed for the second part of the complexation (from the long-lived intermediate to the reaction product) is:

$$
\begin{aligned}
& {\left[\mathrm{Cr}(\mathrm{HYO})\left(\mathrm{H}_{2} \mathrm{O}\right)_{4}\right]^{+} \stackrel{K_{\mathrm{IV}}}{\rightleftarrows}\left[\mathrm{Cr}(\mathrm{OH})(\mathrm{HYO})\left(\mathrm{H}_{2} \mathrm{O}\right)_{3}\right]+\mathrm{H}^{+}} \\
& {\left[\mathrm{Cr}(\mathrm{OH})(\mathrm{HYO})\left(\mathrm{H}_{2} \mathrm{O}\right)_{3}\right] \stackrel{k \mathrm{v} \text { (slow) }}{\underset{k-\mathrm{v}}{\rightleftarrows}}\left[\mathrm{Cr}(\mathrm{OH})(\mathrm{HYO})\left(\mathrm{H}_{2} \mathrm{O}\right)_{2}\right]+\mathrm{H}_{2} \mathrm{O}} \\
& {\left[\mathrm{Cr}(\mathrm{OH})(\mathrm{HYO})\left(\mathrm{H}_{2} \mathrm{O}\right)_{2}\right]+\mathrm{H}_{2} \mathrm{YO}^{-} \stackrel{k_{\mathrm{VI}}}{\longrightarrow}\left[\mathrm{Cr}(\mathrm{OH})(\mathrm{HYO})\left(\mathrm{H}_{2} \mathrm{YO}\right)\left(\mathrm{H}_{2} \mathrm{O}\right)_{2}\right]^{-}} \\
& {\left[\mathrm{Cr}(\mathrm{OH})(\mathrm{HYO})\left(\mathrm{H}_{2} \mathrm{YO}\right)\left(\mathrm{H}_{2} \mathrm{O}\right)_{2}\right]^{-} \longrightarrow\left[\mathrm{Cr}(\mathrm{HYO})_{2}\left(\mathrm{H}_{2} \mathrm{O}\right)_{2}\right]^{-}+\mathrm{H}_{2} \mathrm{O}}
\end{aligned}
$$

Assuming now that the penta-coordinated intermediate formed in the new slow step (forward direction of Eq. (25)) is reactive enough to be in steady state, and applying again to Eq. (24) the quasi-equilibrium approximation, the expression obtained for the second experimental rate constant is as follows:

$$
k_{2}=\frac{K_{\mathrm{IV}} k_{\mathrm{V}} k_{\mathrm{VI}}\left[\mathrm{H}_{2} \mathrm{YO}^{-}\right]}{\left(k_{-\mathrm{V}}+k_{\mathrm{VI}}\left[\mathrm{H}_{2} \mathrm{YO}^{-}\right]\right)\left[\mathrm{H}^{+}\right]}
$$


Equation (28) is consistent with the kinetic data corresponding to the dependences of $k_{2}$ on the concentrations of organic ligand (double-reciprocal linear plot with positive intercept, Fig. 8, bottom) and hydrogen ion (Fig. 9, bottom). Moreover, the increasing effect of the ionic strength might be the result of a combined complex dependence of equilibrium constant $K_{\text {IV }}$ and rate constants $k_{\mathrm{v}}, k_{-\mathrm{v}}$, and $k_{\mathrm{VI}}$. The difference with rate constant $k_{1}$ (decreasing with the ionic strength) may be the consequence of the loss in electrostatic charge of the three complexes involved as reactants in Eqs. (24)-(26) with respect to those involved in Eqs. (19) - (21) caused by the coordination of the anionic ligand $\mathrm{HYO}^{2-}$ to $\mathrm{Cr}(\mathrm{III})$.

Of all the rate constants appearing in Eqs. (23) and (28), the ones suspected to have a biggest incidence in the magnitude of the experimental activation energies are $k_{\text {II }}$ (in relation to $\left.k_{1}\right)$ and $k_{\mathrm{v}}$ (in relation to $\left.k_{2}\right)$. Hence, the notably high values of these parameters $\left(E_{\mathrm{a}, 1}=83\right.$ $\mathrm{kJ} \mathrm{mol}^{-1}$ and $E_{\mathrm{a}, 2}=95 \mathrm{~kJ} \mathrm{~mol}^{-1}$ ) suggest that the loss of an aqua ligand from the first coordination sphere of the metal ion (as in Eqs. (20) and (25)) involves a rather large energy requirement because of the chemical inertness of $\mathrm{Cr}(\mathrm{III})$ complexes.

The global (irreversible) reaction corresponding to Eqs. (19) - (22) and (24) - (27) is:

$$
\left[\mathrm{Cr}\left(\mathrm{H}_{2} \mathrm{O}\right)_{6}\right]^{3+}+2 \mathrm{H}_{2} \mathrm{YO}^{-} \longrightarrow\left[\mathrm{Cr}(\mathrm{HYO})_{2}\left(\mathrm{H}_{2} \mathrm{O}\right)_{2}\right]^{-}+2 \mathrm{H}^{+}+4 \mathrm{H}_{2} \mathrm{O}
$$

according to which, two hydrogen ions are released per chromium atom. However, given enough time ( at $t=\infty$ ), the following equilibria might be reached:

$$
\left[\mathrm{Cr}(\mathrm{HYO})_{2}\left(\mathrm{H}_{2} \mathrm{O}\right)_{2}\right]^{-}+\mathrm{H}_{2} \mathrm{YO}^{-} \rightleftarrows\left[\mathrm{Cr}(\mathrm{HYO})_{3}\right]^{3-}+\mathrm{H}^{+}+2 \mathrm{H}_{2} \mathrm{O}
$$




$$
\begin{gathered}
{\left[\mathrm{Cr}(\mathrm{HYO})_{2}\left(\mathrm{H}_{2} \mathrm{O}\right)_{2}\right]^{-}+\mathrm{H}^{+} \quad \rightleftarrows \quad\left[\mathrm{Cr}\left(\mathrm{HY}_{2} \mathrm{O}\right)\left(\mathrm{H}_{2} \mathrm{O}\right)_{2}\right]+\mathrm{H}_{2} \mathrm{O}} \\
{\left[\mathrm{Cr}(\mathrm{HYO})_{3}\right]^{3-}+2 \mathrm{H}^{+} \rightleftarrows\left[\mathrm{Cr}\left(\mathrm{HY}_{3} \mathrm{O}\right)\right]^{-}+2 \mathrm{H}_{2} \mathrm{O}}
\end{gathered}
$$

where $\mathrm{HY}_{2} \mathrm{O}^{3-}$ and $\mathrm{HY}_{3} \mathrm{O}^{4-}$ stand for the dipeptidic and tripeptidic organic ligands, respectively. According to Eqs. (30)-(32), the concentrations of the product complexes appearing in Eq. (14) are $\left[\mathrm{C}_{n}\right]=\left[\mathrm{Cr}(\mathrm{HYO})_{2}\left(\mathrm{H}_{2} \mathrm{O}\right)_{2}{ }^{-}\right]+\left[\mathrm{Cr}\left(\mathrm{HY}_{2} \mathrm{O}\right)\left(\mathrm{H}_{2} \mathrm{O}\right)_{2}\right](n=2)$ and $\left[\mathrm{C}_{n+1}\right]$ $=\left[\mathrm{Cr}(\mathrm{HYO})_{3}{ }^{3-}\right]+\left[\mathrm{Cr}\left(\mathrm{HY}_{3} \mathrm{O}\right)^{-}\right](n+1=3)$. Moreover, the number of hydrogen ions released to the medium per chromium atom once reached the final equilibrium state can be calculated as:

Number $\left(\mathrm{H}^{+}\right)=\frac{\left[\mathrm{Cr}\left(\mathrm{HY}_{2} \mathrm{O}\right)\left(\mathrm{H}_{2} \mathrm{O}\right)_{2}\right]+\left[\mathrm{Cr}\left(\mathrm{HY}_{3} \mathrm{O}\right)^{-}\right]+2\left[\mathrm{Cr}(\mathrm{HYO})_{2}\left(\mathrm{H}_{2} \mathrm{O}\right)_{2}{ }^{-}\right]+3\left[\mathrm{Cr}(\mathrm{HYO})_{3}{ }^{3-}\right]}{[\mathrm{Cr}(\mathrm{IIII})]_{0}}$

leading to a value in the range $1-3$, depending on the equilibrium concentrations of the four species involved. The asymptotic value of 1.29 experimentally found for an infinite excess of organic ligand with respect to the metal ion (see Eq. (18)) seems to indicate that, under these conditions, the violet product complexes involving a polymerized amino acid ligand (either dipeptidic or tripeptidic) might be predominant over those involving monomeric amino acid ligands (either two or three).

\section{BIBLIOGRAPHY}


1. Kirk, A. D. Chem Rev 1999, 99, 1607-1640.

2. Perez Benito, J. F.; Arias, C.; Rodriguez, R. M. J Phys Chem A 2001, 105, 1150-1157.

3. Ghosh, S. P.; Kumar, M.; Koley, A. P.; Ghosh, M. C. J Chem Res S 2003, 6, 346-347.

4. Bertoni, F. A.; Bellu, S. E.; Gonzalez, J. C.; Sala, L. F. Carbohydr Polym 2014, 114, $1-11$.

5. Mertz, W. Med Clin N Am 1976, 60, 739-744.

6. Mertz, W. J Nutr 1993, 123, 626-633.

7. Schwarz, K.; Mertz, W. Arch Biochem Biophys 1959, 85, 292-295.

8. Weksler-Zangen, S.; Mizrahi, T.; Raz, I.; Mirsky, N. Br J Nutr 2012, 108, 875 - 882.

9. Liu, L.; Cui, W. M.; Zhang, S. W.; Kong, F. H.; Pedersen, M. A.; Wen, Y.; Lv, J. P. RSC Adv 2015, 5, 3482-3490.

10. Cefalu, W. T.; Hu, F. B. Diabetes Care 2004, 27, 2741-2751.

11. Mirsky, N.; Cohen, R.; Eliaz, A.; Dovrat, A. Exp Biol Med 2016, 241, 817-829.

12. Chen, Y.; Watson, H. M.; Gao, J. J.; Sinha, S. H.; Cassady, C. J.; Vincent, J. B. J Nutr $2011,141,1225-1232$.

13. Steams, D. M. Biofactors 2000, 11, 149-162.

14. Vincent, J. B. J Nutr 2017, 147, 2212-2219.

15. McCarty, M. F. Med Hypotheses 1994, 43, 253-265.

16. Sivakumar, S.; Subbhuraam, C. V. Ecotoxicol Environm Safety 2005, 62, 93-98.

17. Takahashi, T.; Toda, E.; Singh, R. B.; De Meester, F.; Wilczynska, A.; Wilson, D.; Juneka, L. R. Open Nutraceut J 2011, 4, $205-212$.

18. Perez Benito, J. F.; Lamrhari, D.; Arias, C. J Phys Chem 1994, 98, 12621 - 12629.

19. Jacob, R. A. Nutr Res $1995,15,755-766$. 
20. Arthur, J. R. Cell Mol Life Sci 2000, 57, 1825-1835.

21. Mahieu, S.; Klug, M.; Millen, N.; Fabro, A.; Benmelej, A.; Contini, M. C. Life Sciences $2016,149,114-119$.

22. Bakac, A.; Espenson, J. H. Acc Chem Res 1993, 26, 519-523.

23. Kornev, V. I.; Mikryukova, G. A. Russ J Coord Chem 2004, 30, 895-899.

24. Perez-Benito, J. F. J Trace Elem Med Biol 2006, 20, 161 - 170.

25. Guindy, N. M.; Abou-Gamra, Z. M.; Abdel-Messih, M. F. J Chim Phys 1999, 96, $851-864$.

26. Guindy, N. M.; Abou-Gamra, Z. M.; Abdel-Messih, M. F. Monatsh Chem 2000, 131, $857-866$.

27. Kitadai, N.; Oonishi, H.; Umemoto, K.; Usui, T.; Fukushi, K.; Nakashima, S. Orig Life Evol Biosph 2017, 47, $123-143$.

28. Remko, M.; Rode, B. M. Struct Chem 2004, 15, 223 - 232.

29. Abdel Messih, M. F.; Abou-Gamra, Z. M. Monatsh Chem 2012, 143, 211 -216.

30. Hamm, R. E. J Am Chem Soc 1953, 75, 5670-5672.

31. Hedrick, C. E. J Chem Educ 1965, 42, 479-480.

32. Barreto, J. C.; Brown, D.; Dubetz, T.; Kakareka, J.; Alberte, R. S. Chem Educator 2005, $10,196-199$.

33. Abdel-Messih, M. F. Adv Chem Eng Sci 2013, 3, 98-104.

34. Roque, C.; Pimienta, V.; Lavabre, D.; Micheau, J. C. J Phys Chem A 2001, 105, $5877-5880$

35. Verma, R. S.; Reddy, M. J.; Shastry, V. R. J Chem Soc, Perkin Trans 2 1976, 469-473.

36. De Andres, J.; Brillas, E.; Garrido, J. A.; Perez-Benito, J. F. J Chem Soc, Perkin Trans 2 $1988,107-112$. 
37. Hu, Y.; Horvath, A. K.; Duan, S. S.; Cseko, G.; Makarov, S. V.; Gao, Q. Y. Eur J Inorg Chem 2015, 5011-5020.

38. Espenson, J. H. Chemical Kinetics and Reaction Mechanisms; McGraw-Hill: New York, 1995.

39. Perez-Benito, J. F. Int J Chem Kinet 2017, 49, 234-249.

40. Perez-Benito, J. F.; Arias, C. Int J Chem Kinet 1991, 23, 717 -732.

41. Perez-Benito, J. F.; Arias, C.; Amat, E. J Colloid Interface Sci 1996, 177, 288 - 297.

42. Perez Benito, J. F.; Ferrando, J. J Phys Chem B 2014, 118, 14949-14960.

43. Perez-Benito, J. F.; Arias, C. Int J Chem Kinet 1993, 25, 221 - 227.

44. Mata-Perez, F.; Perez-Benito, J. F. Can J Chem 1987, 65, $2373-2379$.

45. L’vov, B. V.; Galwey, A. K. Int Rev Phys Chem 2013, 32, 515-557.

46. Coetzee, J. F.; Ritchie, C. D. Solute-Solvent Interactions; Dekker: New York, 1969.

47. Ringbom, A. Complexation in Analytical Chemistry; Interscience: New York, 1963.

48. Gerdom, L. E.; Baenziger, N. A.; Goff, H. M. Inorg Chem 1981, 20, $1606-1609$.

49. Wheeler W. D.; Legg, J. I. Inorg Chem 1984, 23, 3798-3802.

50. Kanamori, K.; Kawai, K. Inorg Chem 1986, 25, 3711-3713.

51. Grubisic, S.; Radanovic, D. D.; Rychlewska, U.; Warzajtis, B.; Draskovic, N. S.; Djuran, M. I.; Niketic, S. R. Polyhedron 2007, 26, 3437 - 3447.

52. Porter, T. L.; Eastman, M. P.; Bain, E.; Begay, S. Biophys Chem 2001, 91, 115-124.

53. Sakata, K.; Yabuta, H.; Kondo, T. Geochem J 2014, 48, 219-230.

54. Griffith, E. C.; Vaida, V. Proc Natl Acad Sci USA 2012, 109, 15697-15701.

55. Volk, L.; Richardson, W.; Lau, K. H.; Hall, M.; Lin, S. H. J Chem Educ 1977, 54, $95-97$.

56. Stünzi, H.; Marty, W. Inorg Chem 1983, 22, 2145-2150. 
57. Galstyan, G.; Knapp, E. W. J Comput Chem 2015, 36, 69-78. 
Table I Kinetic Data at Various Initial Metal Ion Concentrations with Sodium L-Glutamate as Source of Organic Ligands ${ }^{a}$

$[\mathrm{Cr}(\mathrm{III})]_{\mathrm{o}}\left(10^{-2} \mathrm{M}\right) k_{1}\left(10^{-2} \mathrm{~s}^{-1}\right) \quad k_{2}\left(10^{-3} \mathrm{~s}^{-1}\right) \quad \mathrm{pH} \quad E^{\boldsymbol{b}}\left(10^{-4}\right)$

$\begin{array}{lllll}0.59 & 1.77 \pm 0.04 & 2.82 \pm 0.03 & 5.754 \pm 0.006 & 6.80 \pm 0.04 \\ 1.18 & 1.28 \pm 0.07 & 1.99 \pm 0.02 & 5.468 \pm 0.006 & 5.06 \pm 0.51 \\ 1.76 & 1.01 \pm 0.02 & 1.63 \pm 0.03 & 5.283 \pm 0.005 & 4.08 \pm 0.25 \\ 2.35 & 0.92 \pm 0.05 & 1.44 \pm 0.02 & 5.137 \pm 0.001 & 3.95 \pm 0.36 \\ 2.94 & 0.73 \pm 0.04 & 1.24 \pm 0.04 & 5.031 \pm 0.002 & 3.67 \pm 0.28 \\ 3.53 & 0.73 \pm 0.01 & 1.17 \pm 0.02 & 4.934 \pm 0.007 & 3.36 \pm 0.06 \\ 4.12 & 0.73 \pm 0.04 & 1.10 \pm 0.01 & 4.851 \pm 0.007 & 3.34 \pm 0.05 \\ 4.71 & 0.67 \pm 0.01 & 1.04 \pm 0.01 & 4.762 \pm 0.002 & 3.38 \pm 0.21 \\ 5.29 & 0.60 \pm 0.02 & 1.04 \pm 0.02 & 4.682 \pm 0.004 & 3.91 \pm 0.17 \\ 5.88 & 0.58 \pm 0.02 & 0.98 \pm 0.01 & 4.609 \pm 0.004 & 3.61 \pm 0.05 \\ 6.47 & 0.55 \pm 0.01 & 0.99 \pm 0.01 & 4.529 \pm 0.004 & 3.48 \pm 0.27\end{array}$

${ }^{a}[\text { Ligand }]_{\mathrm{O}}=0.392 \mathrm{M}, 25.0^{\circ} \mathrm{C}$

${ }^{b}$ Average error of the calculated absorbances with respect to the experimental values. 
Table II Activation Parameters Associated to the Experimental Rate Constants with LGlutamic Acid as Source of Organic Ligands ${ }^{a}$

\begin{tabular}{cccc} 
Rate Constant & $E_{\mathrm{a}}\left(\mathrm{kJ} \mathrm{mol}^{-1}\right)$ & $\Delta H_{\ddagger}^{\mathrm{o}}\left(\mathrm{kJ} \mathrm{mol}^{-1}\right)$ & $\Delta S_{\ddagger}^{\mathrm{o}}\left(\mathrm{J} \mathrm{K} \mathrm{K}^{-1} \mathrm{~mol}^{-1}\right)$ \\
\hline$k_{1}$ & $83 \pm 10$ & $80 \pm 10$ & $-27 \pm 35$ \\
$k_{2}$ & $95 \pm 5$ & $92 \pm 5$ & $-6 \pm 15$
\end{tabular}

${ }^{a}[\mathrm{Cr}(\mathrm{III})]_{\mathrm{o}}=5.88 \times 10^{-3} \mathrm{M},[\text { ligand }]_{\mathrm{o}}=3.92 \times 10^{-2} \mathrm{M},[\mathrm{KOH}]_{\mathrm{o}}=4.05 \times 10^{-2} \mathrm{M}, \mathrm{pH} 4.09 \pm$ $0.02,15.0-25.0{ }^{\circ} \mathrm{C}$. 


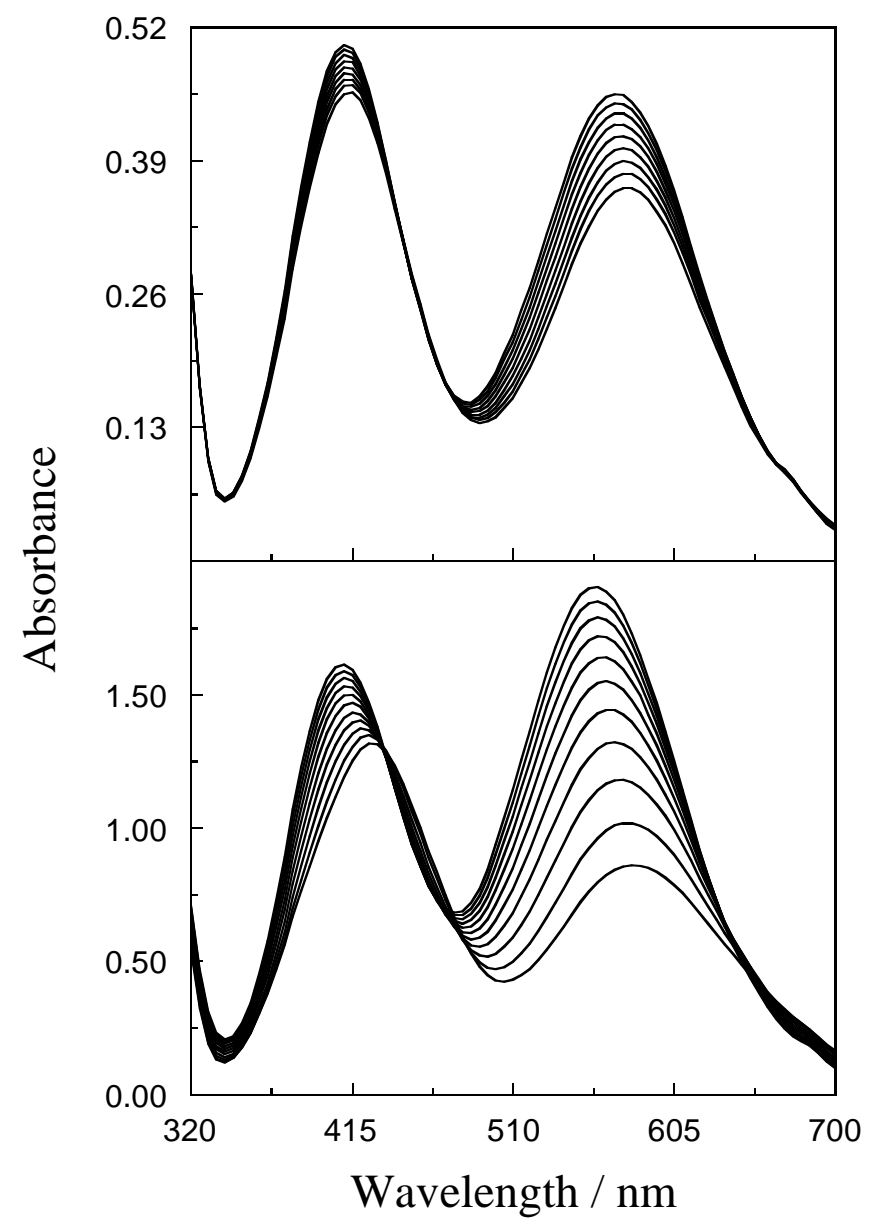

Figure 1 Periodic scannings of the UV-Vis spectrum of the reacting mixture with either Lglutamic acid (top, $[\mathrm{Cr}(\mathrm{III})]_{\mathrm{o}}=2.65 \times 10^{-2} \mathrm{M},[\text { ligand }]_{\mathrm{o}}=3.92 \times 10^{-2} \mathrm{M},[\mathrm{KOH}]_{\mathrm{o}}=1.62 \times 10^{-2}$ $\mathrm{M}, \mathrm{pH} 2.59, \Delta t=60 \mathrm{~min}$ ) or sodium hydrogen L-glutamate (bottom, $[\mathrm{Cr}(\mathrm{III})]_{\mathrm{o}}=5.29 \times 10^{-2}$ $\mathrm{M},[\text { ligand }]_{\mathrm{o}}=0.392 \mathrm{M}, \mathrm{pH} 4.68, \Delta t=3 \mathrm{~min}$ ) as source of organic ligands at $25.0{ }^{\circ} \mathrm{C}$. The progress of the reaction corresponds to the increase of both absorption peaks. 


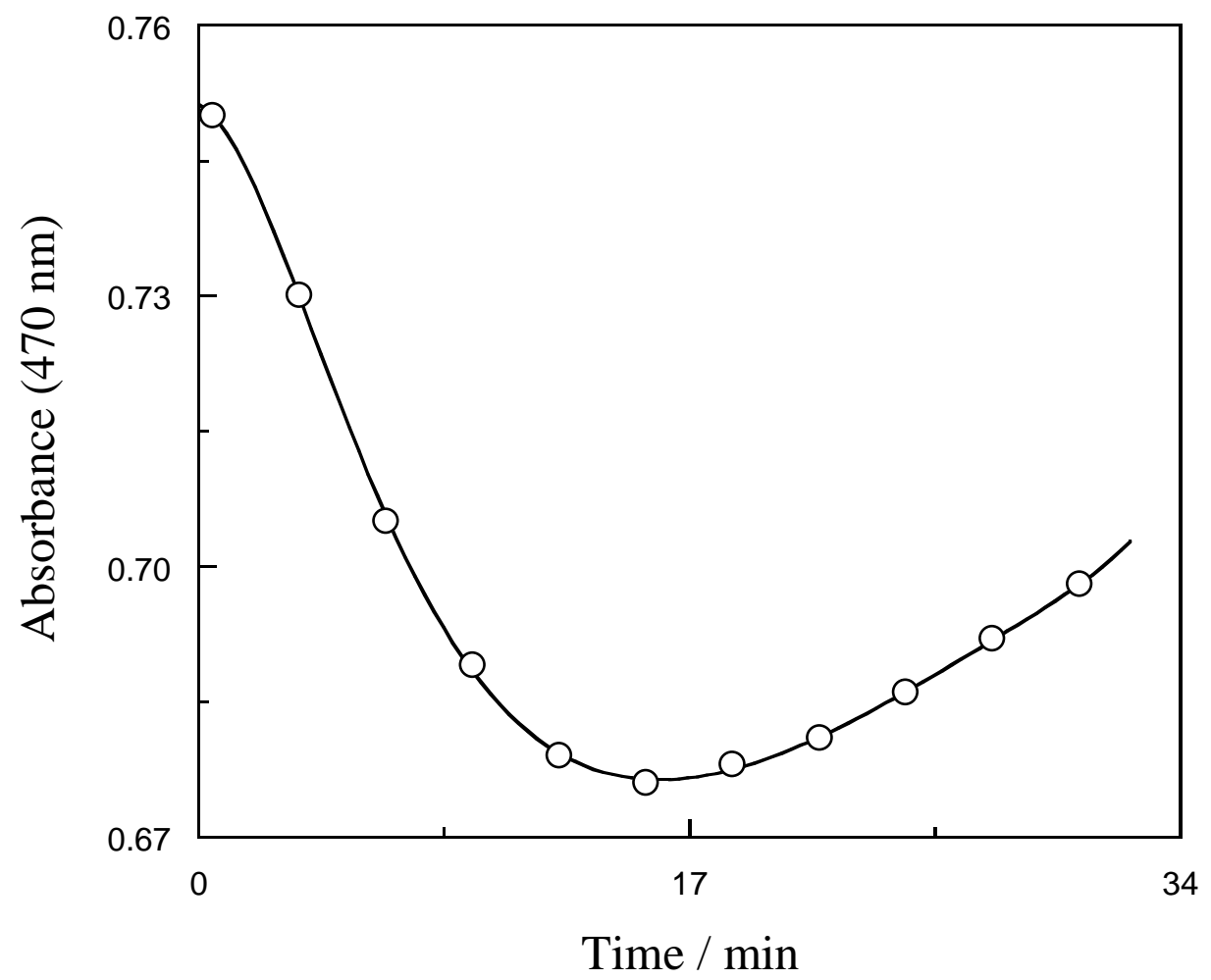

Figure 2 Absorbance at $470 \mathrm{~nm}$ as a function of time with sodium hydrogen L-glutamate as source of organic ligands. $[\mathrm{Cr}(\mathrm{III})]_{\mathrm{o}}=5.29 \times 10^{-2} \mathrm{M},[\text { ligand }]_{\mathrm{o}}=0.392 \mathrm{M}, \mathrm{pH} 4.68,25.0^{\circ} \mathrm{C}$. 


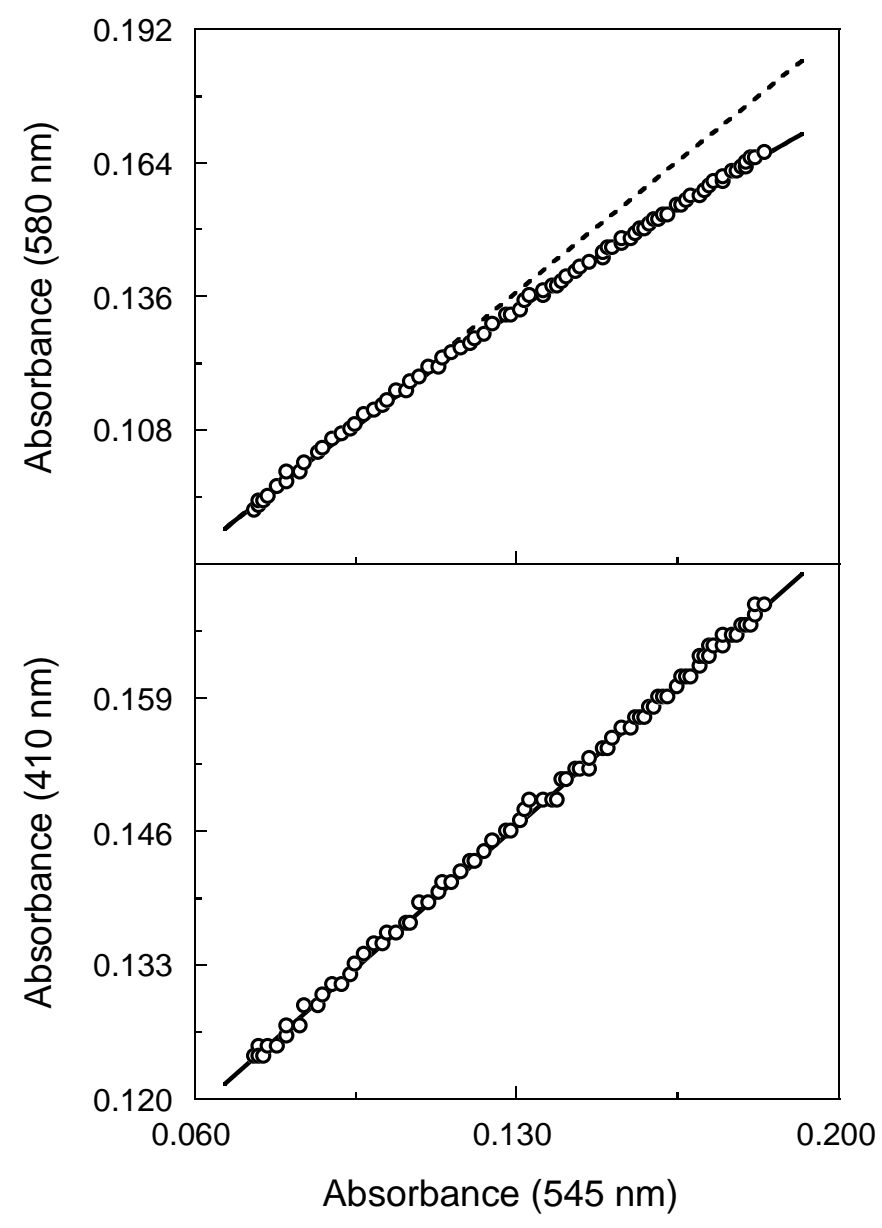

Figure 3 Absorbance at 580 (top) and 410 (bottom) nm as a function of the absorbance at $545 \mathrm{~nm}$ during the course of the reaction with L-glutamic acid as source of organic ligands. The dashed line is the tangent to the curve at $t=0 .[\mathrm{Cr}(\mathrm{III})]_{\mathrm{o}}=5.88 \times 10^{-3} \mathrm{M}$, [ligand $]_{\mathrm{o}}=$ $3.43 \times 10^{-2} \mathrm{M},[\mathrm{KOH}]_{\mathrm{o}}=2.03 \times 10^{-2} \mathrm{M}, \mathrm{pH} 3.45(t=\infty), 25.0^{\circ} \mathrm{C}$. 


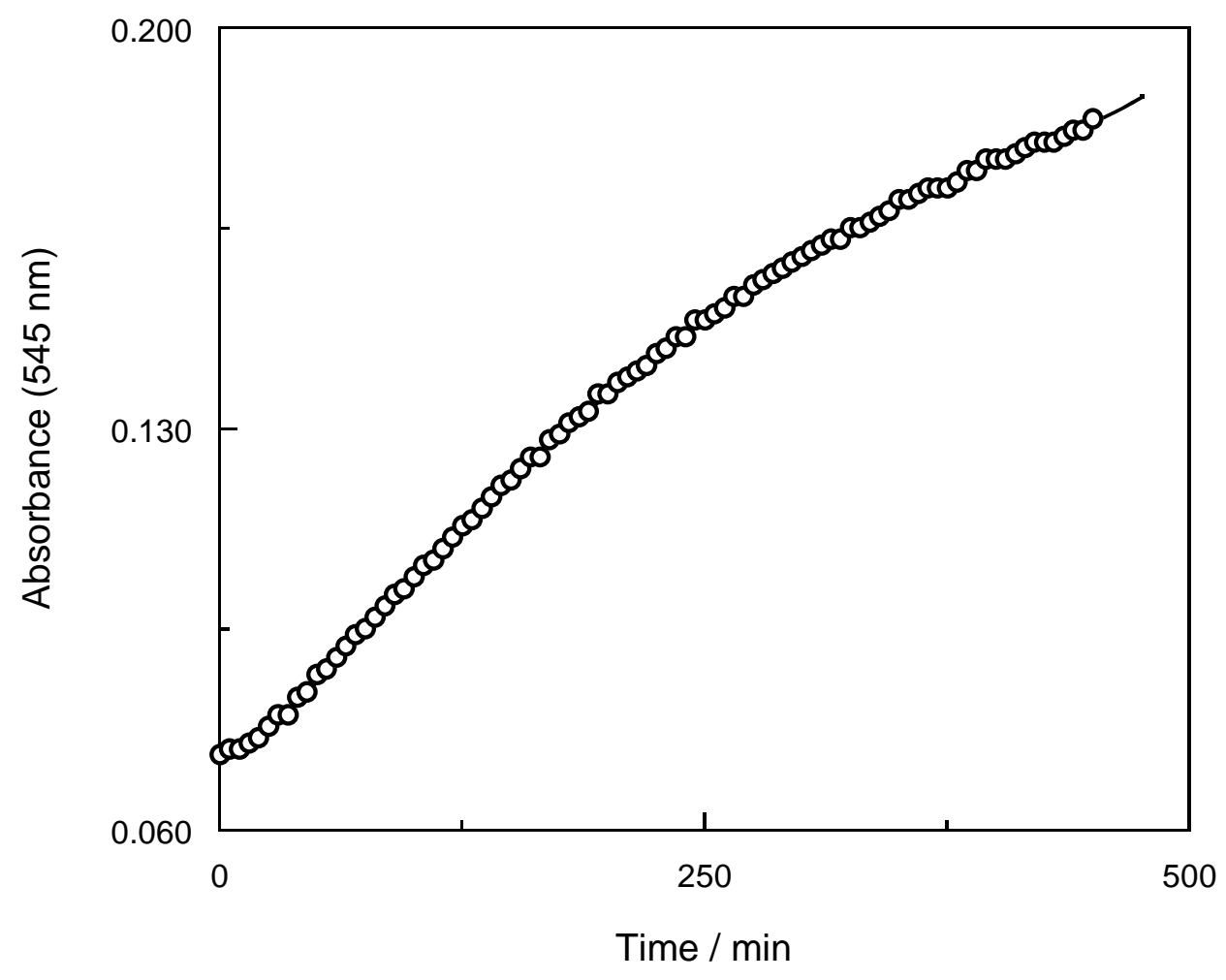

Figure 4 Absorbance at $545 \mathrm{~nm}$ as a function of time during the course of the reaction with L-glutamic acid as source of organic ligands. $[\mathrm{Cr}(\mathrm{III})]_{\mathrm{o}}=5.88 \times 10^{-3} \mathrm{M},[\text { ligand }]_{\mathrm{o}}=$ $3.43 \times 10^{-2} \mathrm{M},[\mathrm{KOH}]_{\mathrm{o}}=2.03 \times 10^{-2} \mathrm{M}, \mathrm{pH} 3.45,25.0{ }^{\circ} \mathrm{C}$. 


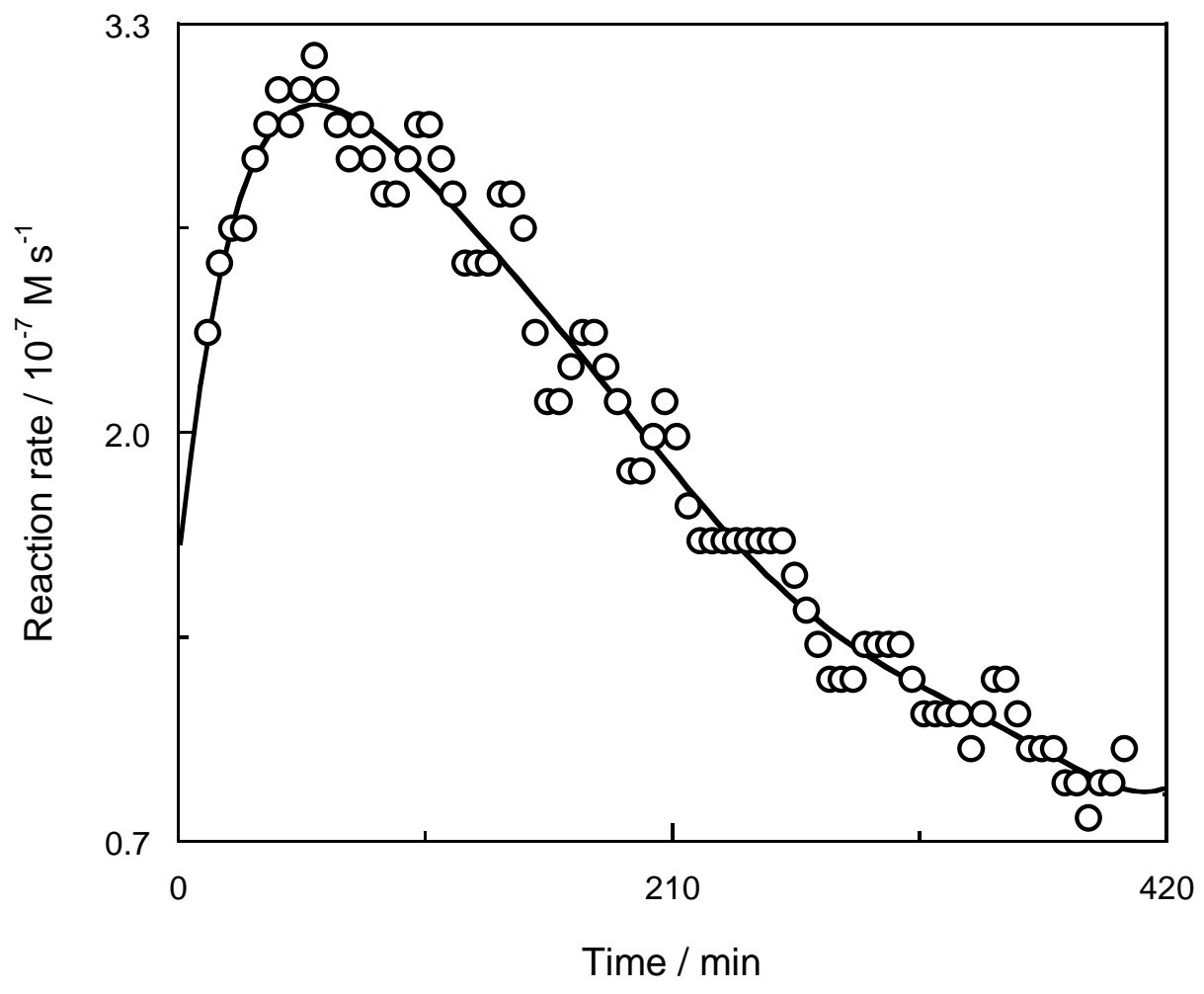

Figure 5 Reaction rate as a function of time during the course of the reaction with Lglutamic acid as source of organic ligands. $[\mathrm{Cr}(\mathrm{III})]_{\mathrm{o}}=5.88 \times 10^{-3} \mathrm{M},[\text { ligand }]_{\mathrm{o}}=3.92 \times 10^{-2}$ $\mathrm{M},[\mathrm{KOH}]_{\mathrm{o}}=2.85 \times 10^{-2} \mathrm{M}, \mathrm{pH} 3.63,25.0^{\circ} \mathrm{C}$. 


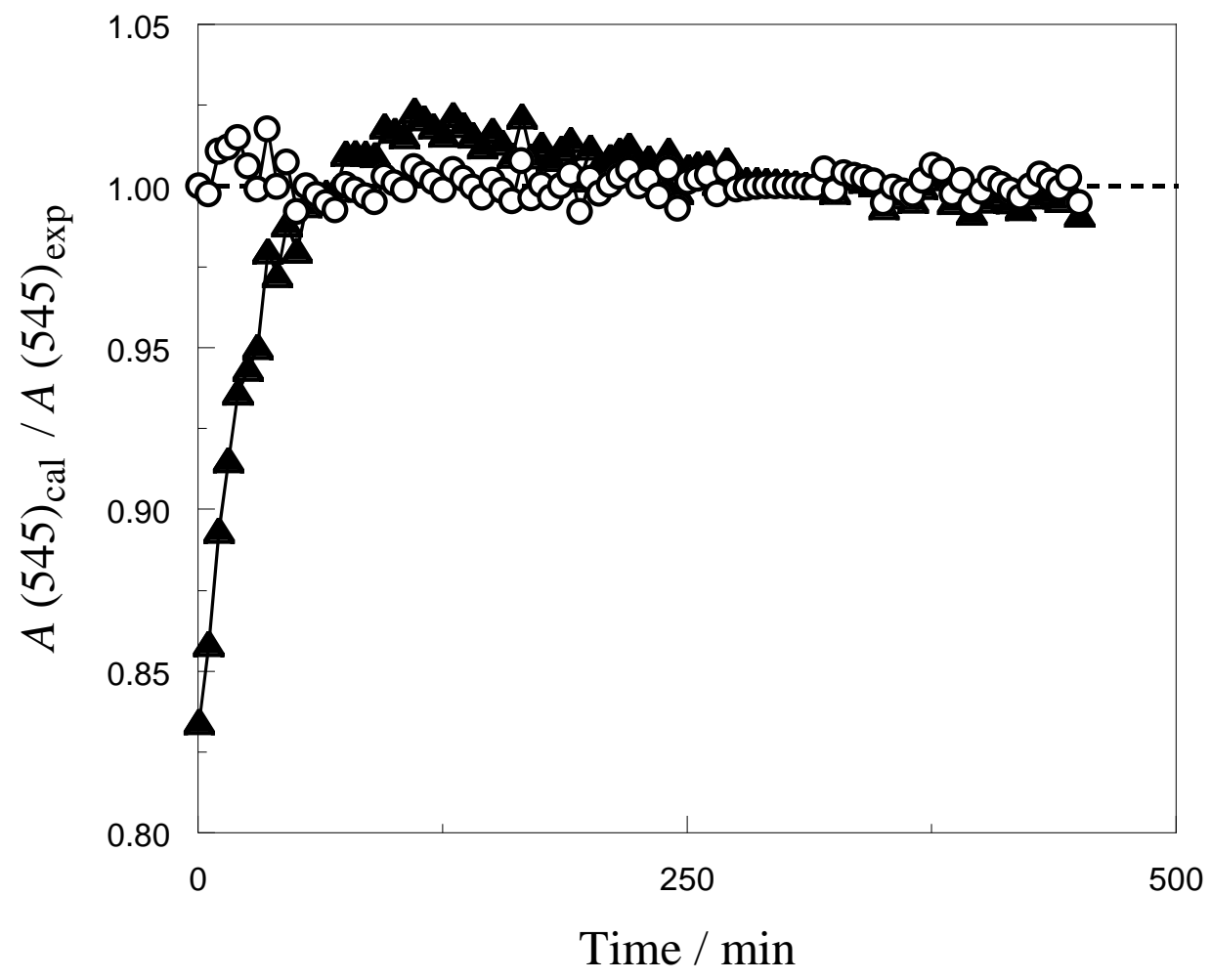

Figure 6 Ratio between the calculated and experimental absorbances at $545 \mathrm{~nm}$ as a function of time during the course of the reaction with L-glutamic acid as source of organic ligands. Triangles: one rate constant (pseudo-first order) kinetic model. Circles: two rate constant (double-exponential) kinetic model $[\mathrm{Cr}(\mathrm{III})]_{\mathrm{o}}=5.88 \times 10^{-3} \mathrm{M},[\text { ligand }]_{\mathrm{o}}=3.43 \times 10^{-2} \mathrm{M}$, $[\mathrm{KOH}]_{\mathrm{o}}=2.03 \times 10^{-2} \mathrm{M}, \mathrm{pH} 3.45,25.0^{\circ} \mathrm{C}$. 


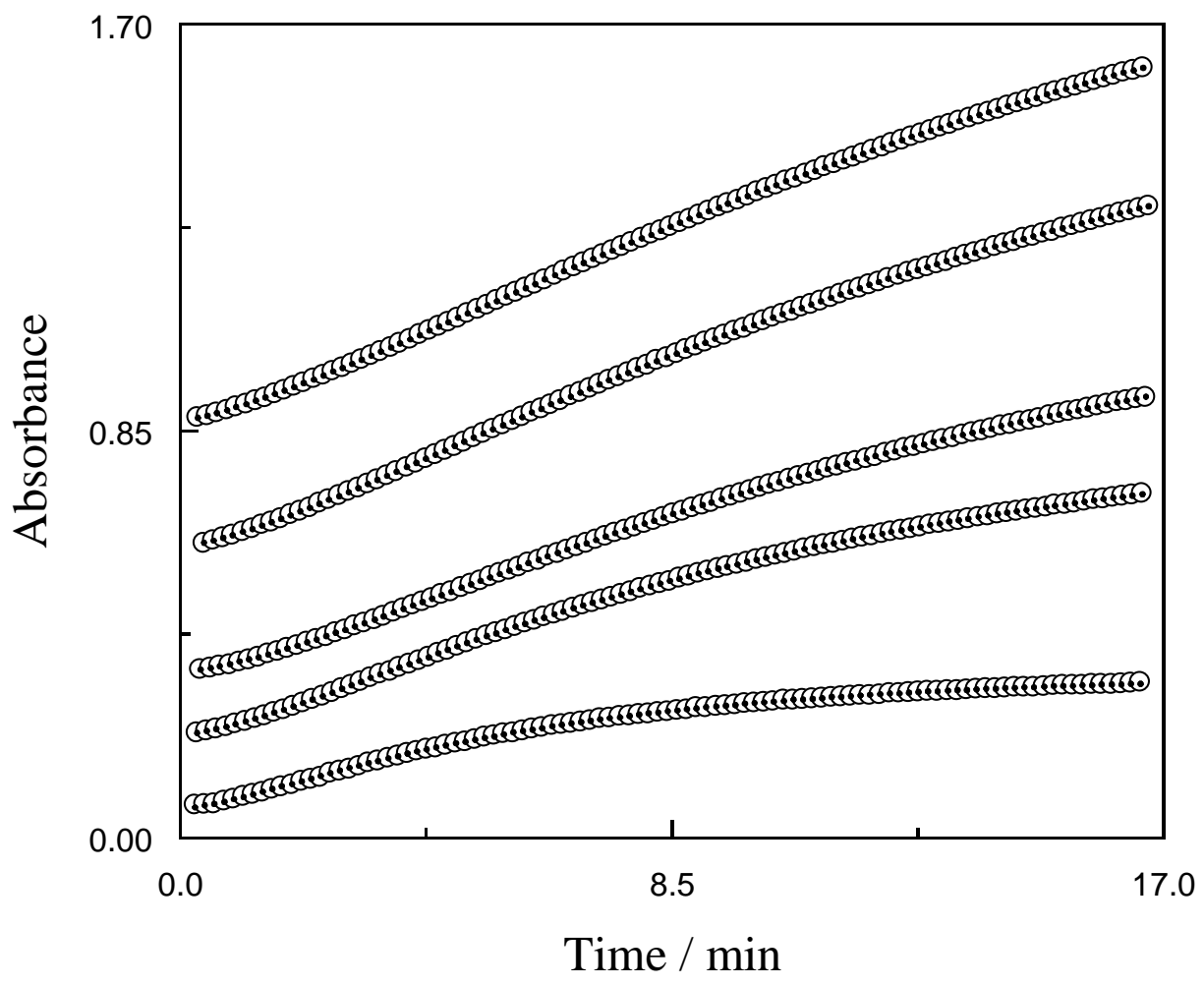

Figure 7 Absorbance-time kinetic plots at different initial concentrations of metal ion with sodium hydrogen L-glutamate as source of organic ligands. From bottom to top: $[\mathrm{Cr}(\mathrm{III})]_{\mathrm{o}}=$ 0.59 (first), 1.76 (second), 2.94 (third), 4.70 (fourth), and 6.47 (fifth) $\times 10^{-2} \mathrm{M}$, [ligand $]_{\mathrm{o}}=$ $0.392 \mathrm{M}, \mathrm{pH} 4.53-5.75,25.0^{\circ} \mathrm{C}$. The circles correspond to the experimental absorbances and the black points inside to the absorbances calculated according to the double-exponential function. 


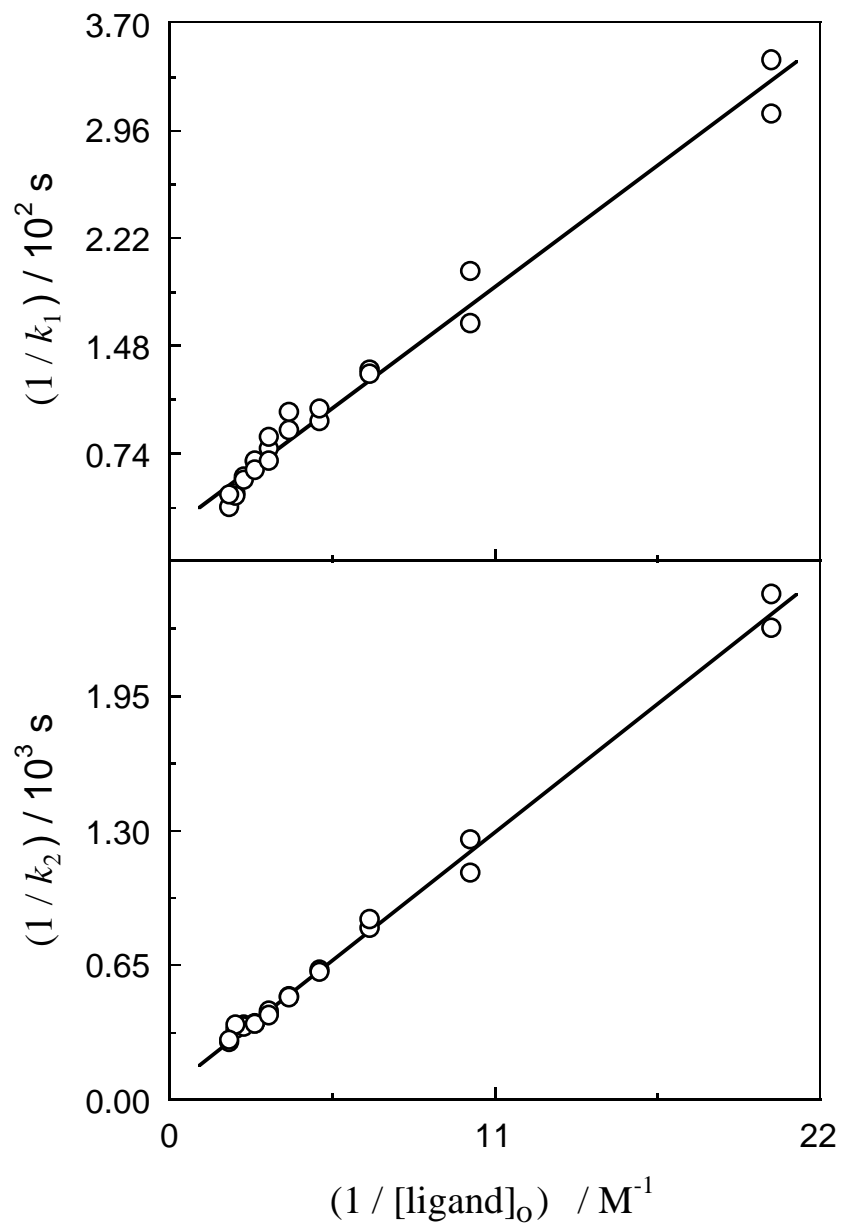

Figure 8 Double-reciprocal linear plots of the experimental rate constants $k_{1}$ (top, $r=0.990$ ) and $k_{2}$ (bottom, $r=0.998$ ) as a function of the initial ligand concentration with sodium hydrogen L-glutamate as source of organic ligands. $[\mathrm{Cr}(\mathrm{III})]_{\mathrm{o}}=5.88 \times 10^{-3} \mathrm{M}$, $[\text { ligand }]_{\mathrm{o}}=$ $0.049-0.490 \mathrm{M}, \mathrm{pH} 4.77-5.87,25.0^{\circ} \mathrm{C}$. 


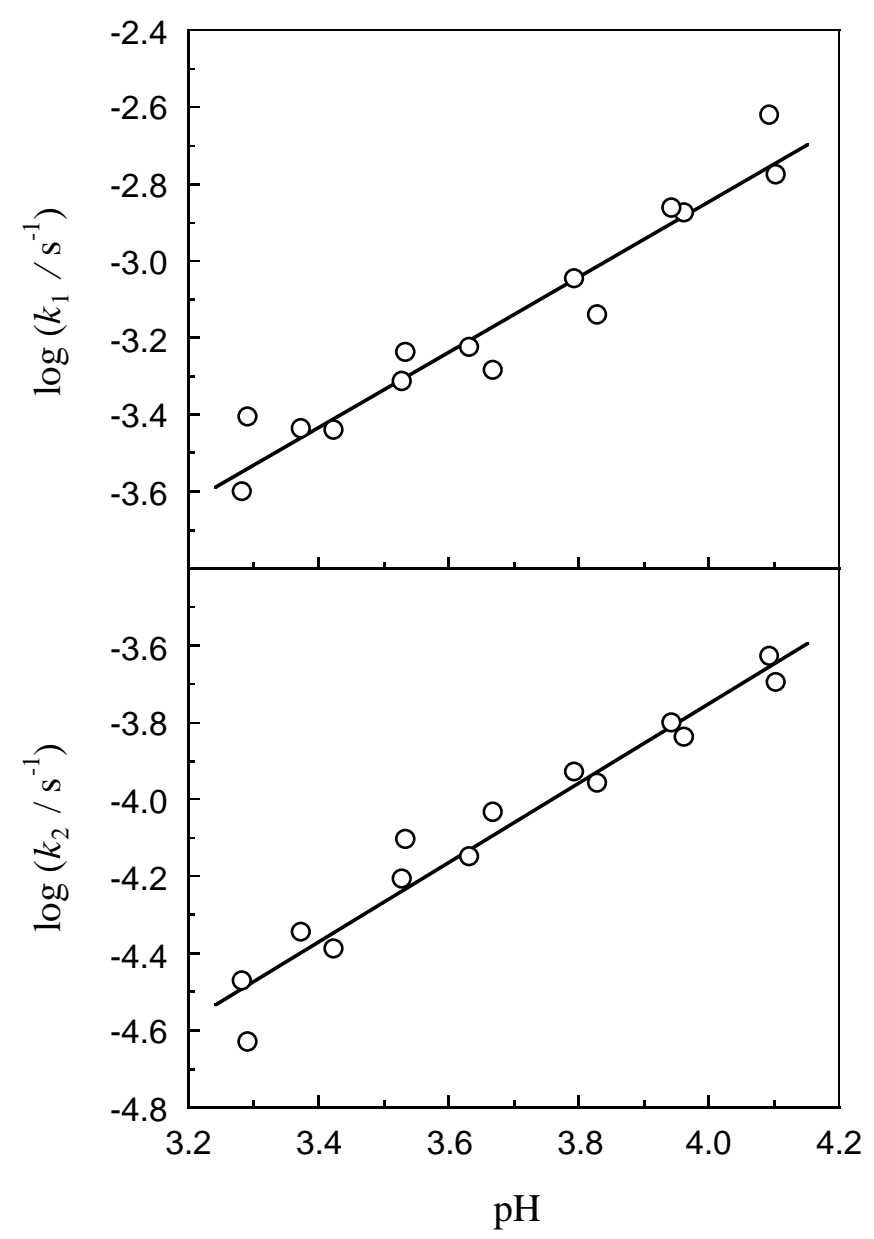

Figure 9 Dependence of the experimental rate constants $k_{1}$ (top, $r=0.964$ ) and $k_{2}$ (bottom, $r$ $=0.976)$ on the $\mathrm{pH}$ with L-glutamic acid as source of organic ligands. $[\mathrm{Cr}(\mathrm{III})]_{\mathrm{o}}=5.88 \times 10^{-3}$ $\mathrm{M},[\text { ligand }]_{\mathrm{o}}=3.92 \times 10^{-2} \mathrm{M},[\mathrm{KOH}]_{\mathrm{o}}=(1.59-4.07) \times 10^{-2} \mathrm{M}, 25.0^{\circ} \mathrm{C}$. 


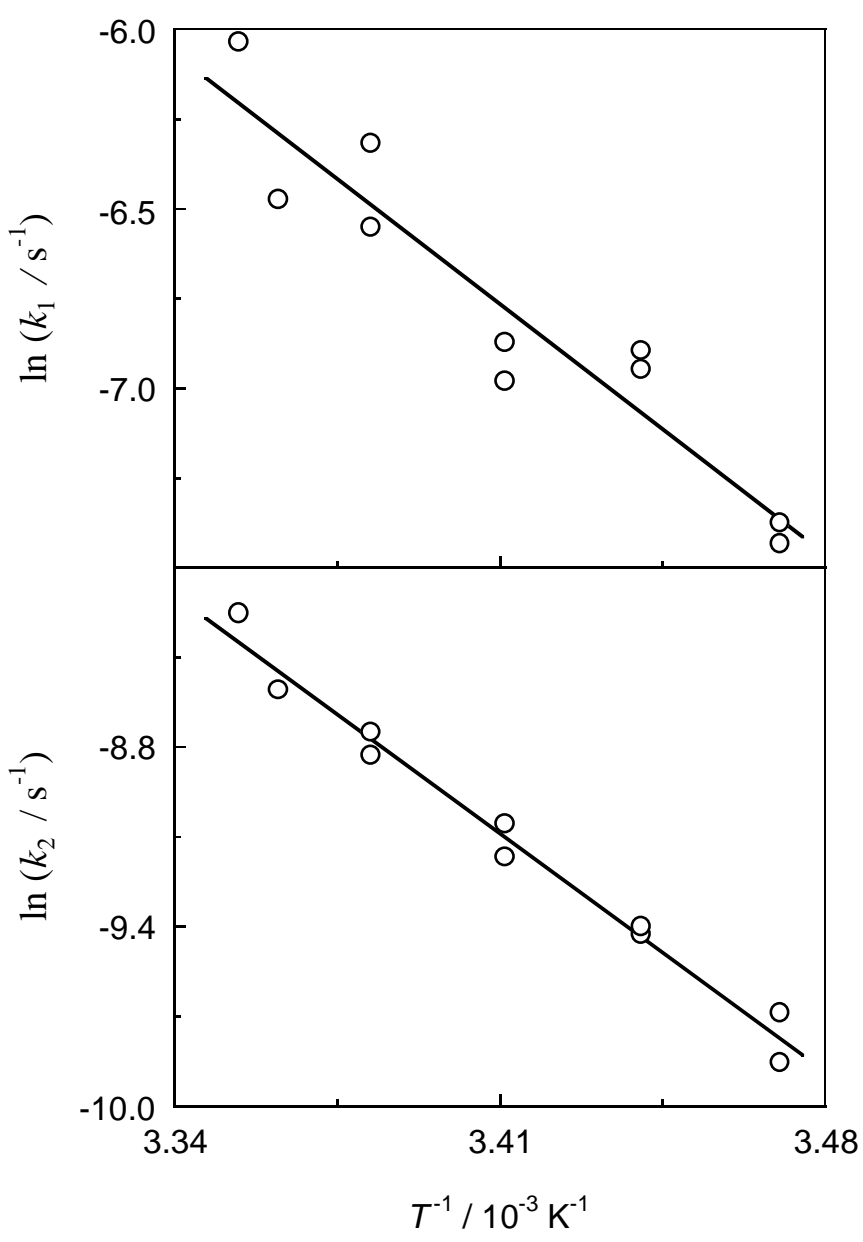

Figure 10 Arrhenius plots for the experimental rate constants $k_{1}$ (top, $r=0.944$ ) and $k_{2}$ (bottom, $r=0.991$ ) with L-glutamic acid as source of organic ligands. $[\mathrm{Cr}(\mathrm{III})]_{\mathrm{o}}=5.88 \times 10^{-3}$ $\mathrm{M},[\text { ligand }]_{\mathrm{o}}=3.92 \times 10^{-2} \mathrm{M},[\mathrm{KOH}]_{\mathrm{o}}=4.05 \times 10^{-2} \mathrm{M}, \mathrm{pH} 4.09 \pm 0.02,15.0-25.0^{\circ} \mathrm{C}$. 


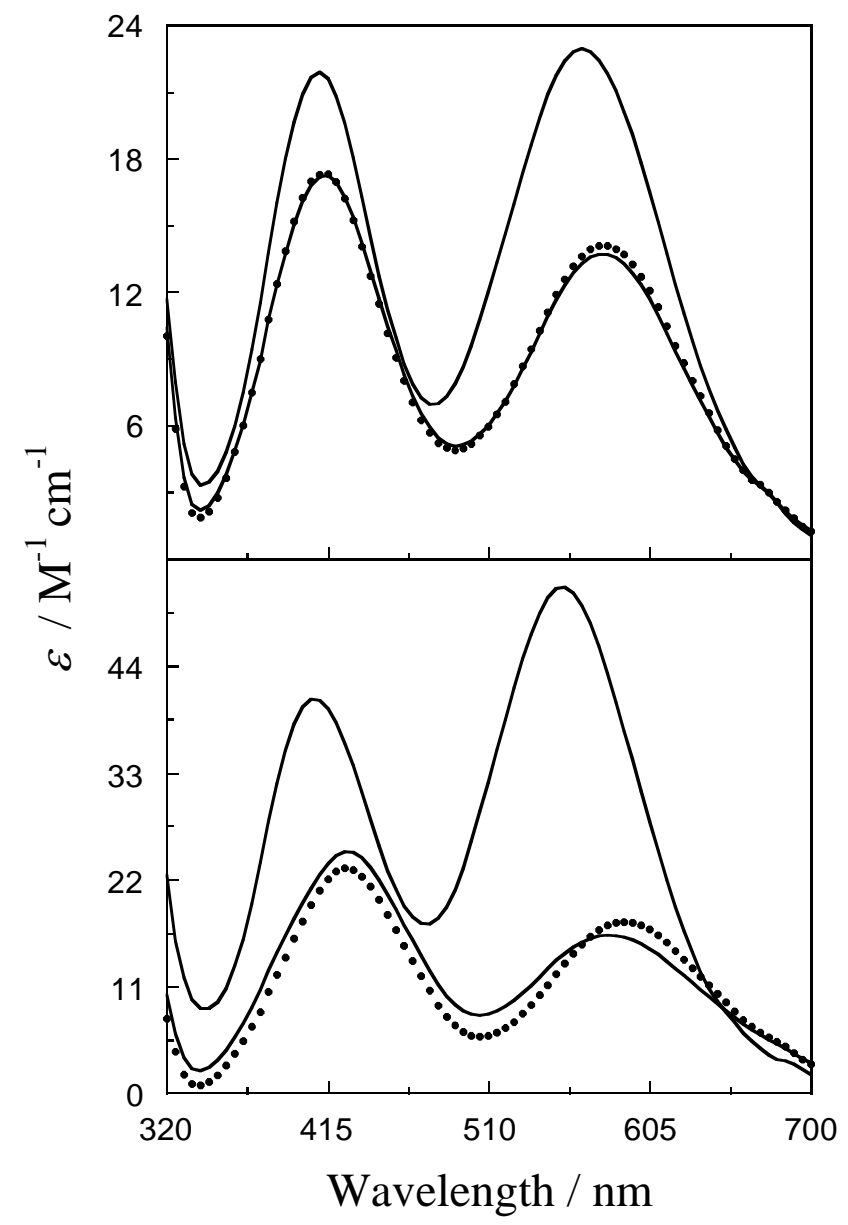

Figure 11 Molar absorption coefficients as a function of the wavelength for the UV-Vis spectra of three $\mathrm{Cr}$ (III) complexes: reactant (lower continuous line), long-lived intermediate (dotted line), and final product (upper continuous line) with either L-glutamic acid (top, $\left.[\mathrm{Cr}(\mathrm{III})]_{\mathrm{o}}=2.65 \times 10^{-2} \mathrm{M},[\text { ligand }]_{\mathrm{o}}=3.92 \times 10^{-2} \mathrm{M},[\mathrm{KOH}]_{\mathrm{o}}=1.62 \times 10^{-2} \mathrm{M}, \mathrm{pH} 2.59\right)$ or sodium hydrogen L-glutamate (bottom, $[\mathrm{Cr}(\mathrm{III})]_{\mathrm{o}}=5.29 \times 10^{-2} \mathrm{M},[\text { ligand }]_{\mathrm{o}}=0.392 \mathrm{M}, \mathrm{pH}$ 4.68) as source of organic ligands at $25.0{ }^{\circ} \mathrm{C}$. 


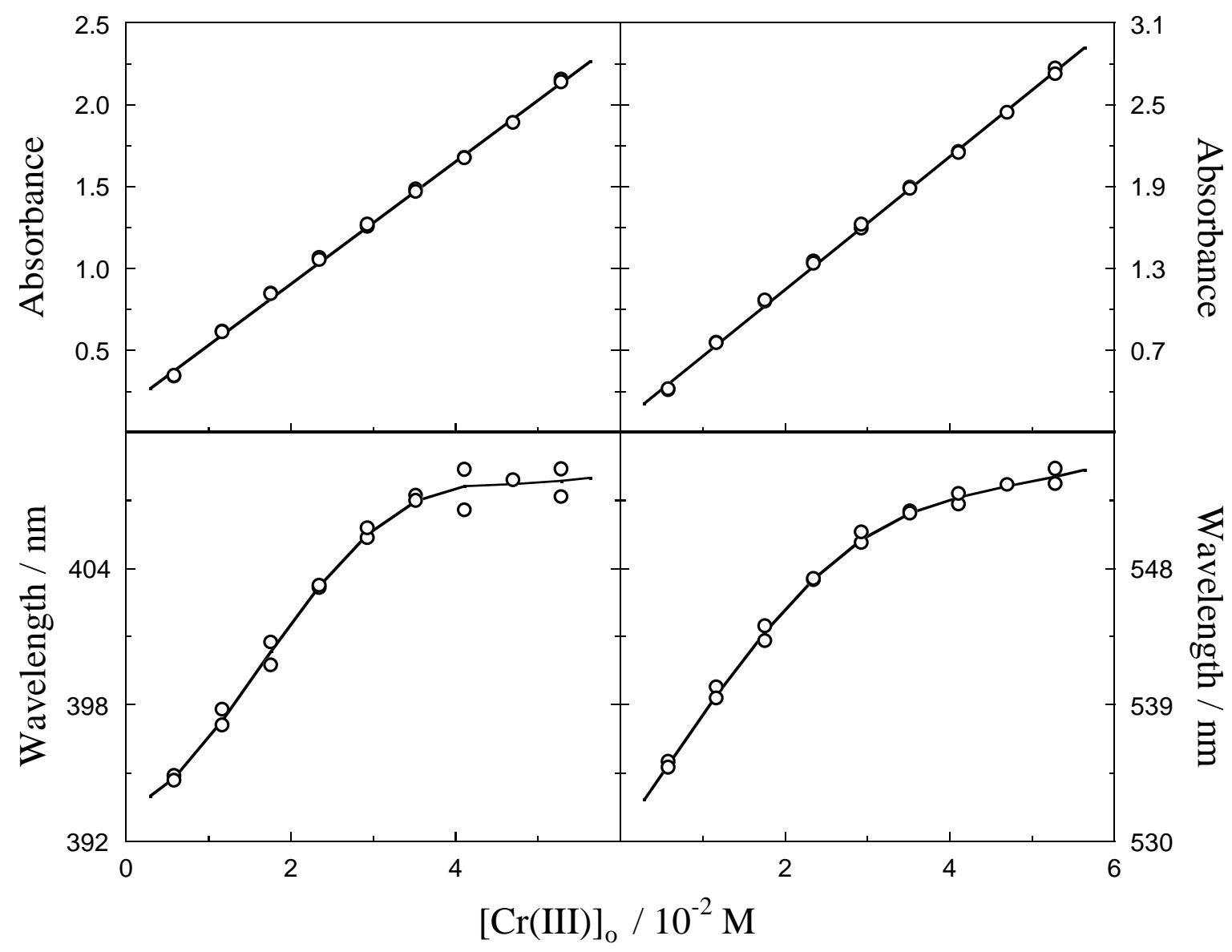

Figure 12 Wavelengths (bottom) and absorbances (top) corresponding to the first (left) and second (right) peaks of the electronic spectrum recorded for the final violet complex as a function of the metal ion initial concentration with sodium hydrogen L-glutamate as source of organic ligands at $[\mathrm{Cr}(\mathrm{III})]_{\mathrm{o}}=(0.59-5.29) \times 10^{-2} \mathrm{M},[\text { ligand }]_{\mathrm{o}}=0.392 \mathrm{M}, \mathrm{pH} 4.68-5.75$, and $25.0^{\circ} \mathrm{C}$. 


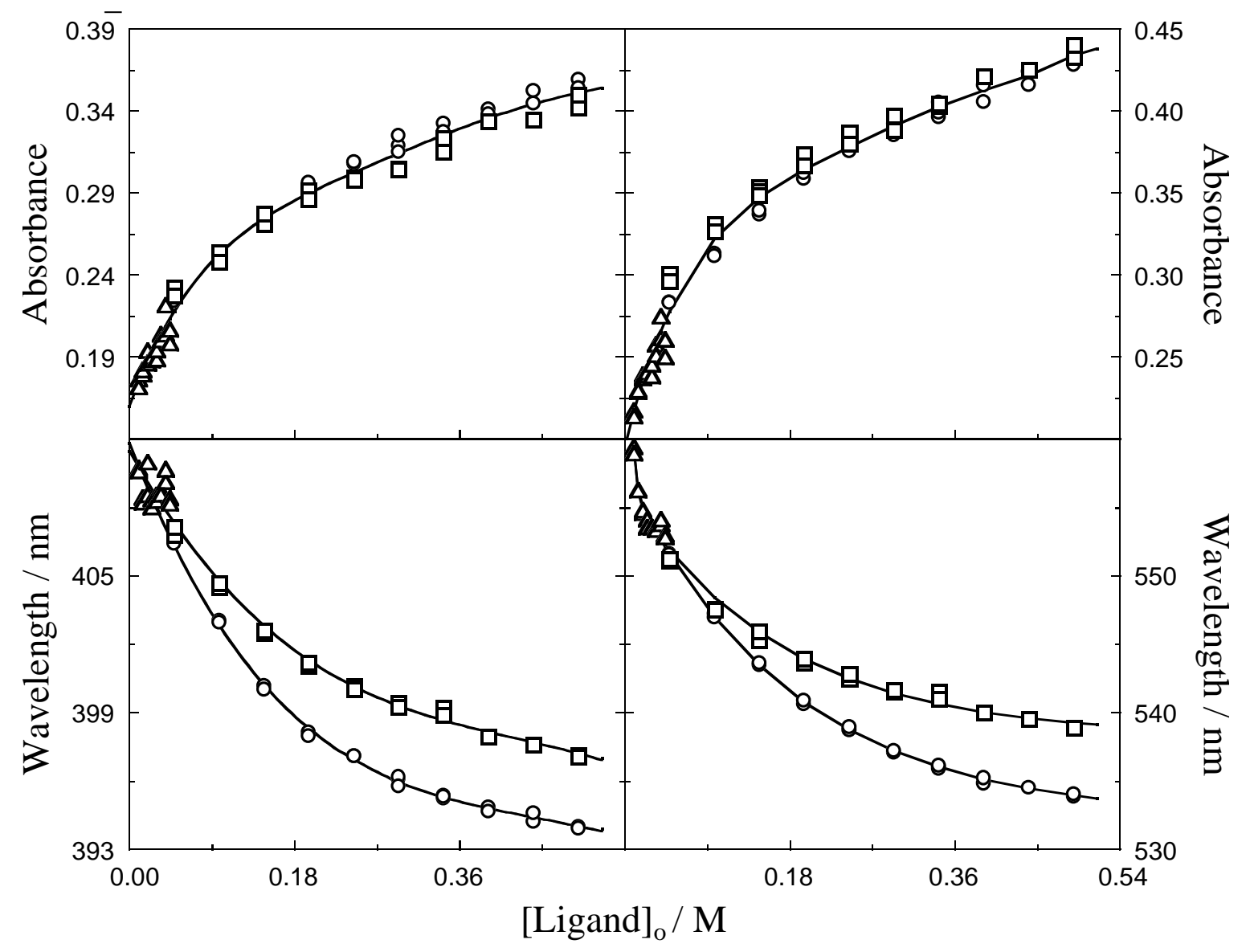

Figure 13 Wavelengths (bottom) and absorbances (top) corresponding to the first (left) and second (right) peaks of the electronic spectrum recorded for the final violet complex as a function of the organic ligand initial concentration at $[\mathrm{Cr}(\mathrm{III})]_{\mathrm{o}}=5.88 \times 10^{-3} \mathrm{M}$ and $25.0^{\circ} \mathrm{C}$. Triangles: $[\text { L-glutamic acid }]_{\mathrm{o}}=(0.98-4.41) \times 10^{-2} \mathrm{M},[\mathrm{KOH}]_{\mathrm{o}}=1.96 \times 10^{-2} \mathrm{M}, \quad \mathrm{pH}$ 3.37-3.88. Squares: [L-glutamic acid $]_{\mathrm{o}}=0.049-0.490 \mathrm{M},[\mathrm{KOH}]_{\mathrm{o}}=0.059-0.589 \mathrm{M}, \mathrm{pH}$ $4.43-5.01$. Circles: [sodium hydrogen L-glutamate $]_{\mathrm{o}}=0.049-0.490 \mathrm{M}, \mathrm{pH} 4.77-5.87$. 


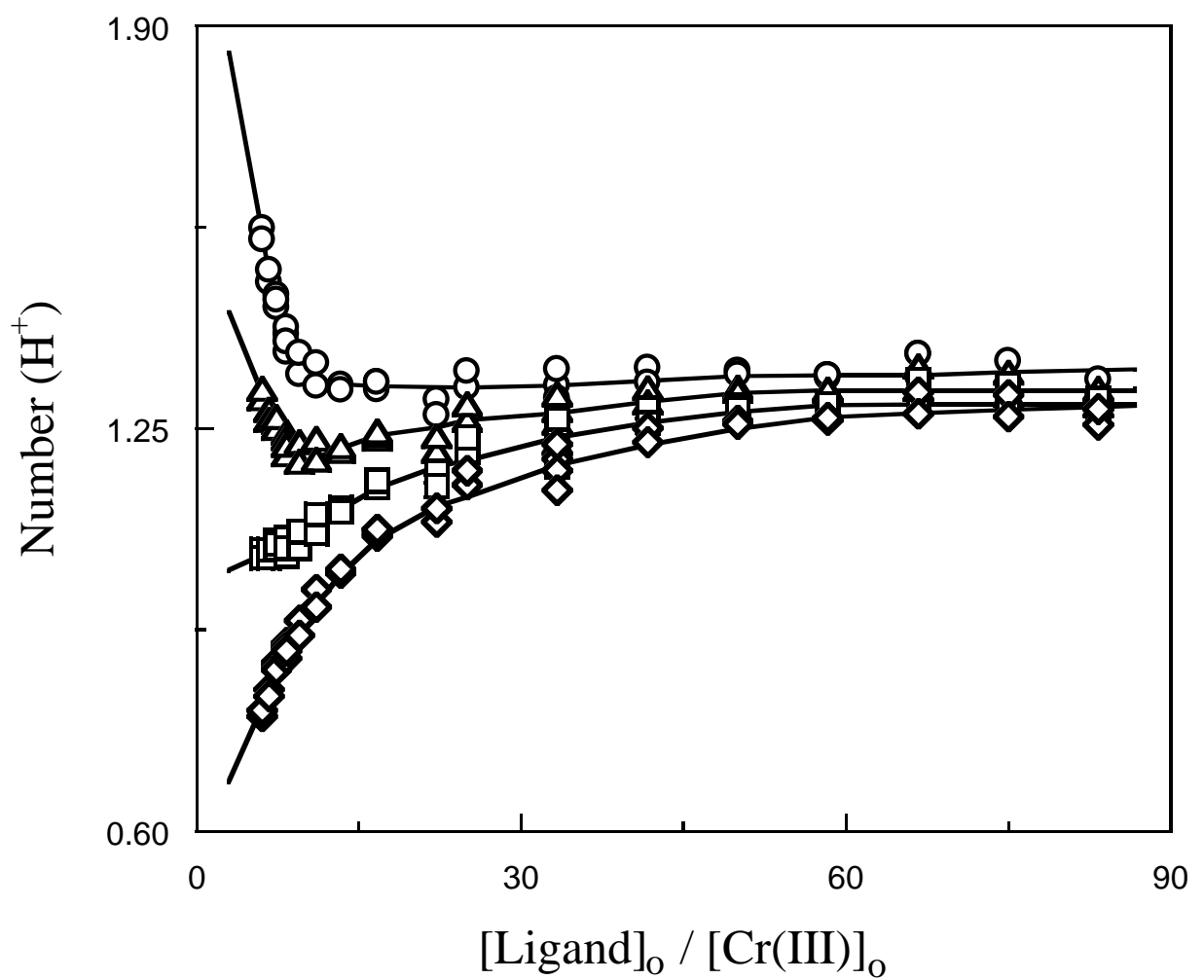

Figure 14 Number of hydrogen ions released to the medium by sodium hydrogen Lglutamate per chromium atom to form the final violet complex as a function of the ligand/metal initial concentration ratio assuming different coordination numbers: $n=0$ (circles), 1 (triangles), 2 (squares), and 3 (rhombuses). $[\mathrm{Cr}(\mathrm{III})]_{\mathrm{o}}=(0.59-6.47) \times 10^{-2} \mathrm{M}$, $[\text { ligand }]_{\mathrm{o}}=0.049-0.490 \mathrm{M}, \mathrm{pH} 4.53-5.87,25.0^{\circ} \mathrm{C}$. 